\title{
New bichalcone analogs as NF-KB inhibitors and as cytotoxic agents inducing Fas/CD95-dependent apoptosis
}

\author{
M. Vijaya Bhaskar Reddy ${ }^{a}$, Yuh-Chiang Shen ${ }^{b}$, Tsong-Long Hwang ${ }^{C}$, Kenneth F. Bastow ${ }^{d}$,

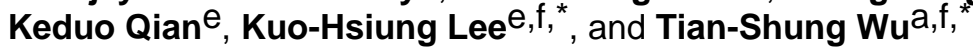 \\ aDepartment of Chemistry, National Cheng Kung University, Tainan 701, Taiwan \\ bNational Research Institute of Chinese Medicine, Taipei, Taiwan 112 \\ 'Graduate Institute of Natural Products, College of Medicine, Chang Gung University, 259, \\ Taoyan, Taiwan \\ ${ }^{d}$ Division of Medicinal Chemistry and Natural Products, UNC Eshelman School of Pharmacy, \\ University of North Carolina, Chapel Hill, North Carolina 27599, USA \\ eNatural Products Research Laboratories, UNC Eshelman School of Pharmacy, University of \\ North Carolina, Chapel Hill, North Carolina 27599, USA \\ ${ }^{f}$ Chinese Medicine Research and Development Center and Department of Pharmacy, China \\ Medical University and Hospital, Taichung, Taiwan
}

\section{Abstract}

\begin{abstract}
A series of novel bichalcone analogs were synthesized and evaluated in lipopolysaccharide (LPS)activated microglial cells as inhibitors of nitric oxide (NO) and for in vitro anticancer activity using a limited panel of four human cancer cell lines. All analogs inhibited NO production. Compounds 4 and 11 exhibited optimal activity with $\mathrm{IC}_{50}$ values of 0.3 and $0.5 \mu \mathrm{M}$, respectively, and were at least 38 -fold better than the positive control. A mechanism of action study showed that both compounds significantly blocked the nuclear translocation of NF- $\mathrm{kB}$ p65 and upregulation of iNOS at $1.0 \mu \mathrm{M}$. Compound 4 and three other analogs $(\mathbf{3}, \mathbf{2 0}$, and 23) exerted significant in vitro anticancer activity $\mathrm{GI}_{50}$ values ranging from $0.70 \sim 13.10 \mu \mathrm{M}$. A mode of action study using HT-29 colon cancer cells showed that $\mathbf{2 3}$ acts by inducing apoptosis signaling.
\end{abstract}

\section{Keywords}

bichalcone analogs; nitric oxide production inhibition; cytotoxicity; apoptosis

\section{Introduction}

Dietary flavonoids, commonly present in edible plants, are known to have beneficial effects, such as antioxidative effects, tumor cell growth inhibitory activity, and apoptosis induction

(c) 2011 Elsevier Ltd. All rights reserved.

*To whom correspondence should be addressed. For TS Wu, Tel.: +886-6-2747538; Fax: 886-2-2740552; tswu@ mail.ncku.edu.tw; For KH Lee, Tel.: +1-919-9620066; Fax: +1-919-9663893; khlee@unc.edu.

${ }^{+}$Equal contribution.

Publisher's Disclaimer: This is a PDF file of an unedited manuscript that has been accepted for publication. As a service to our customers we are providing this early version of the manuscript. The manuscript will undergo copyediting, typesetting, and review of the resulting proof before it is published in its final citable form. Please note that during the production process errors may be discovered which could affect the content, and all legal disclaimers that apply to the journal pertain. 
in cancer cell lines. Therefore, dietary flavonoids have attracted attention as chemopreventive agents. ${ }^{1}$ Chalcones are the immediate precursors in the biosynthesis of flavonoids, and their structure differs considerably from the other members of the flavonoid family. Chalcones are reported with diverse biological activities including antiinflammatory, anti-malarial, anti-protozoal, anti-bacterial, nitric oxide inhibition, tyrosinase inhibition, cytotoxic, anticancer, and anti-leishmanial activities. ${ }^{2-6}$ The bichalcones are well represented in the Anacardiacea family. The Rhus genus is also a rich source for biflavonoids and bichalcones. In general, naturally occurring bichalcones carry either C-O-C or C-C linkage between the two chalcone units. Although natural bichalcones from Rhus pyroides demonstrated varying degrees of cytotoxic activity against different cancer cell lines, they showed more selectivity toward colon cancer cell lines, especially the HT29 and HCT-116 cell lines. ${ }^{7}$

The Mannich base reaction is an important carbon-carbon bond-forming reaction in organic synthesis, and it has been widely utilized in the synthesis of nitrogen-containing drugs, natural products and biologically active compounds. ${ }^{8,9}$ Considering the pharmacological importance of bichalcones, we synthesized a series of bichalcone analogs through the piperazine Mannich base linkage with different substitutions in the B-ring of the chalcone moiety. Target compounds were examined as inhibitors of nitric oxide (NO) production in lipopolysaccharide (LPS)-activated microglial cells, which are important free radicalproducing cells in the central nervous system. Rapid production of reactive oxygen species (ROS) by NADPH oxidase (NOX) and nitric oxide (NO) by NO synthase (NOS) can be generated experimentally. ${ }^{10}$ Thus, we investigated the expression of iNOS protein and NF$\kappa B$ p65 (C) and p65 (N) in presence of bichalcone analogs. In addition, we further evaluated the in vitro anticancer activity of the newly synthesized compounds against four human cancer cell lines, and explored the mechanism of action of a selected compound (23) in the HT-29 human colon adenocarcinoma cell line.

\section{Chemistry}

4-Hydroxyacetophenone (1) and 4-hydroxy-3-methoxyacetophenone (2) were reacted with 4-piperazinoacetophenone and paraformaldehyde in $\mathrm{EtOH}$ at $120^{\circ} \mathrm{C}$ for $18-22 \mathrm{~h}$ to obtain C-5 substituted Mannich base derivatives 1a and 2a, respectively (Scheme 1). Target compounds 3-20 were obtained by the reaction of 1a or 2a with substituted aldehydes under Claisen-Schmidt conditions using 30\% $\mathrm{KOH}$ in $\mathrm{MeOH}$ at $\mathrm{rt}$ (Scheme 2). Compounds $\mathbf{1 b}$ and $1 \mathbf{c}$ were obtained by the reaction of $\mathbf{1}$ with pyrrole-2-carboxaldehyde and $\mathrm{N}$ methylpyrrole-2-carboxaldehyde, and $\mathbf{2 b}$ was obtained by the reaction of $\mathbf{2}$ with 3pyridinecarboxaldehyde under Claisen-Schmidt conditions. The target chalcones 21, 22, and $\mathbf{2 3}$ were prepared by the further reaction of $\mathbf{1 b}, \mathbf{1 c}$, and $\mathbf{2 b}$ with 4-piperazinoacetophenone and paraformaldehyde in $\mathrm{EtOH}$ at $120^{\circ} \mathrm{C}$ for $18-22 \mathrm{~h}$ (Scheme 3).

\section{Results and discussion}

Other laboratories have found that chalcone compounds can function as potent NF- $\mathrm{KB}$ inhibitors ${ }^{11}$ and inhibit NO production. ${ }^{12}$ Based on these precedents, our new compounds 1a-23 were evaluated for inhibition of NOX-dependent ROS production and NOSdependent NO production in microglial cells as well as for 1,1-diphenyl-2-picrylhydrozyl (DPPH) radical scavenging capacity. None of the compounds showed inhibition of NOXdependent ROS production or ability for direct radical-scavenging in a cell-free DPPH solution. In contrast, 1a-23 were potent inhibitors of NO production in microglial cells with $\mathrm{IC}_{50}$ values ranging from 0.3 to $30.5 \mu \mathrm{M}$, compared with L-nitroarginine methyl ester (LNAME) $\left(\mathrm{IC}_{50}: 18.9 \mu \mathrm{M}\right)$, a specific NOS inhibitor (Table 1). 
To summarize the initial structure-activity observations on the bichalcone analogs, we found that a methoxy group at the $\mathrm{C}-3$ position in the A-ring resulted in weaker NO production inhibition activity compared with no substitution at this position, as seen with $1 \mathbf{b}\left(\mathrm{IC}_{50}: 15.9\right.$ $\mu \mathrm{M})$ versus $1 \mathrm{a}\left(\mathrm{IC}_{50}: 6.6 \mu \mathrm{M}\right)$. Concerning the B-ring, 3 and $\mathbf{4}$ with 2-pyridyl and 3-pyridyl B-rings, respectively, showed improved activity with $\mathrm{IC}_{50}$ values of 1.4 and $0.3 \mu \mathrm{M}$, respectively. Compounds $5\left(\mathrm{IC}_{50}: 1.7 \mu \mathrm{M}\right)$ and $6\left(\mathrm{IC}_{50}: 1.9 \mu \mathrm{M}\right)$ with 2-furanyl and 2thiophenyl B-rings, respectively, showed similar NO inhibition activity to that of $\mathbf{3}$. Adding methyl groups at the $\mathrm{C}-3$ or $\mathrm{C}-5$ position of the thiophene or furan rings decreased the compounds' activity, as seen with $\mathbf{7}$ and $\mathbf{8}$. The introduction of a methoxy group at the C-4 position of the phenyl B-ring of $\mathbf{1 1}$ resulted in increased inhibition of $\mathrm{NO}$ production $\left(\mathrm{IC}_{50}\right.$ : $0.5 \mu \mathrm{M}$ ), while addition of chloro substituents on the B-ring as in $\mathbf{1 3}$ and $\mathbf{1 4}$ led to decreased inhibition of $\mathrm{NO}$ production ( $\mathrm{IC}_{50}: 30.5$ and $25.7 \mu \mathrm{M}$, respectively).

The influence of the most potent NO production inhibitors $\mathbf{4}$ and $\mathbf{1 1}$ on the iNOS protein expression and NF- $\mathrm{KB}$ signaling pathway was further explored in LPS-activated BV2 cells (Figure 1). Both compounds significantly blocked the nuclear translocation of NF- $\mathrm{kB}$ p65 at $1.0 \mu \mathrm{M}$ concentration and decreased the iNOS protein expression. These results suggested that $\mathbf{4}$ and $\mathbf{1 1}$ may target the NF-кB signaling pathway to block iNOS up-regulation, which in turn suppresses the NO production.

Compounds 1a-23 were also evaluated for cytotoxicity against four human cancer cell lines, DU145 (prostate cancer), A549 (non small cell lung cancer), KB (nasopharyngeal carcinoma) and HCT-8 (ileocecal) (Table 2). It was found that the B-ring pyridyl moiety is important for significant activity of the bichalcone analogs $3\left(\mathrm{GI}_{50}: 1.08 \sim 1.26 \mu \mathrm{M}\right), 4\left(\mathrm{GI}_{50}\right.$ : 1.40 2.19 $\mu \mathrm{M})$, and $20\left(\mathrm{GI}_{50}: 0.70 \sim 3.98 \mu \mathrm{M}\right)$. Compound 23, bearing a single B-ring pyridyl moiety, also showed activity, but with higher $\mathrm{GI}_{50}$ values $(9.77$ to $13.1 \mu \mathrm{M})$. Compounds 21 and $\mathbf{2 2}$ with one pyrrole B-ring showed marginal cytotoxicity, and all the other analogs tested were essentially inactive.

As shown in Figure 2A, 23 inhibited HT-29 cell viability in a dose-dependent manner. HT-29 cells were then treated with $\mathbf{2 3}$ at a fixed concentration $(30 \mu \mathrm{M})$, and cell viability was determined over time up to three days. As shown in Figure 2B, 23 inhibited HT-29 cell viability in a time-dependent manner. Figures $3 \mathrm{~A}$ and $\mathrm{B}$ show the results from phasecontrast microscopy of 23-treated HT-29 cells coupled with DAPI staining for the occurrence of morphological changes and DNA condensation. Following treatment with $\mathbf{2 3}$ (30 and $50 \mu \mathrm{M}$ ), HT-29 cells exhibited nuclear shrinkage and chromatin condensation, compared to the untreated control cells. To further investigate 23's effect on the DNA of HT-29 cells, we assessed the DNA fragmentation by terminal deoxynucleotidyl transferasemediated dUTP nick end labeling staining (TUNEL) coupled with flow cytometry. As shown in Figure 4, $23(30 \mu \mathrm{M})$ induced DNA fragmentation in HT-29 cells in a timedependent manner. This response is associated with apoptosis, so the effects of $\mathbf{2 3}$ on the signaling pathway were investigated.

The activities of caspase- $3,-8$, and -9 in 23-treated HT-29 cells detected by colorimetric enzymatic assay are shown in Figure 5A. All of the active caspases were detected after $24 \mathrm{~h}$ treatment with $\mathbf{2 3}$. To verify the involvement of caspase-3, -8 , and -9 in $\mathbf{2 3}$-induced apoptosis of HT-29 cells, inhibitors of each caspase (caspase-3, Z-DEVE-FMK; caspase-8, Z-IETD-FMK; caspase-9, Z-LEHD-FMK) were used. The results shown in Figure 5B are consistent with 23 inducing apoptosis through the activation of caspase- $-3,-8$, and -9 . The relative levels of 12 key apoptosis-associated protein levels in 23-treated HT-29 cells were then analyzed using Western Blot Analysis. Compound $\mathbf{2 3}$ increased the protein expression of Fas/CD95, FADD (Figure 6A), cytosolic cytochrome c, Apaf-1, AIF, Endo G (Figure 6B), caspase-3 (Figure 6C), Bax (Bcl2-associated X protein), and t-Bid (Fig 6D), and 
decreased the protein levels of pro-caspase-8, pro-caspase-9 (Figure 6C) and Bcl-2 (Figure $6 \mathrm{D})$. The analysis results suggested that $\mathbf{2 3}$ induces apoptosis in HT-29 cells via both death receptor (Fas/CD95) and mitochondrial-dependent pathways. ${ }^{13-15}$ The effects of $\mathbf{2 3}$ on the proteins analyzed and the interactions of these proteins within the Fas/CD95 and mitochondrial-dependent pathways are shown graphically on the left and right sides, respectively, of Figure 7.

In summary, a series of bichalcones with a piperazine Mannich base linkage was prepared and evaluated for inhibition of NO production in microglial cells and for in vitro anticancer activity. Compounds $\mathbf{4}$ and $\mathbf{1 1}$ were potent inhibitors of cellular NO production in LPSactivated microglial cells, likely indirectly via blockade of NF- $\mathrm{KB}$ p65 nuclear translocation. Several bichalcone analogs, including $\mathbf{4}$ as well as $\mathbf{3 , 2 0}$, and $\mathbf{2 3}$, with a signature pyridyl moiety also showed significant activity against human tumor cell replication. Exploration of the mechanism of action showed that $\mathbf{2 3}$ likely acted via the Fas/CD95 apoptosis signaling pathway.

\section{Experimental Section}

\subsection{Materials and Methods}

Melting points were determined using a Yanagimoto MP-S3 micro-melting point apparatus and are uncorrected. IR spectra were determined on a Shimadzu FT-IR Prestige 21 spectrophotometer. ${ }^{1} \mathrm{H}$ and ${ }^{13} \mathrm{C}$ NMR spectra were recorded on a Bruker Avance 300 spectrometer, using tetramethylsilane (TMS) as internal standard; all chemical shifts are reported in parts per million (ppm, $\delta$ ). FABMS and HRFABMS spectra were obtained on a JEOL JMS-700 mass spectrometer. Column chromatography was performed on silica gel (70-230 mesh, 230-400 mesh). TLC was conducted on precoated Kieselgel 60 F254 plates (Merck), and the spots were detected by UV. Elemental analyses were determined by Elementer Vario EL III and gave combustion values for C, H, N and S. Concentration of the reaction solutions involved the use of rotary evaporator under reduced pressure. All other chemicals were obtained from Aldrich, Inc. Dimethyl sulfoxide (DMSO), 3-(4,5dimethylthiazol-2-yl)-2,5-diphenyltetrazolium bromide (MTT), 4',6-diamidino-2phenylindole (DAPI), Tris- $\mathrm{HCl}$ and Triton X-100 were obtained from Sigma Chemical Co. (St. Louis, MO, USA). Caspase-8 inhibitor, z-Ile-Glu-Thr-Asp-fluoromethyl ketone (ZIETD-FMK), Caspase-9 inhibitor, z-Leu-Glu-His-Asp-fluoromethyl ketone (Z-LEHDFMK), Caspase-3 inhibitor z-Asp-Met-Gln-Asp-fluoromethyl ketone (Z-DEVD-FMK) (R\&D, USA) were dissolved in DMSO and diluted in cell culture medium before use. RPMI 1640, penicillin-streptomycin, trypsin-EDTA, fetal bovine serum (FBS), and glutamine were obtained from Gibco BRL (Invitrogen, Grand Island, NY).

\subsection{General procedure for the synthesis of Mannich bases of acetophenones}

To a solution of hydroxy-substituted acetophenone and paraformaldehyde in EtOH (75 mL) was added 4-piperazinoacetophenone at rt as per reported earlier literature. ${ }^{16-19}$ Then the resulting mixture was heated to reflux for $18-22 \mathrm{~h}$ at $120^{\circ} \mathrm{C}$. On completion, the reaction mixture was concentrated under reduced pressure and the crude product was purified by column chromatography to yield the ortho substituted Mannich base in good yield (Scheme $1)$.

\subsubsection{1-(4-(4-(5-Acetyl-2-hydroxybenzyl)piperazin-1-yl)phenyl)ethanone (1a)-} Compound 1 (13.6 g, $100 \mathrm{mmol})$, paraformaldehyde $(3.0 \mathrm{~g}, 100 \mathrm{mmol})$ and $4-$ piperizinoacetophenone $(20.4 \mathrm{~g}, 100 \mathrm{mmol})$ were treated as described above. The crude product was purified by CC eluting with (i- $\mathrm{Pr})_{2} \mathrm{O} / \mathrm{MeOH}(9: 1)$ to yield 1a (colorless crystalline solid, $24.5 \mathrm{~g}, 69.6 \%$ ), $\mathrm{mp} 146-148{ }^{\circ} \mathrm{C}$. IR (neat) $3005,2711,1666,1597,1519$, 
1442, 1357, 1284, 1238, 1195, 1118, 1002, 925, 825, 756, 690, 563, $513 \mathrm{~cm}^{-1} .{ }^{1} \mathrm{H} \mathrm{NMR}$ $\left(\mathrm{CDCl}_{3}, 300 \mathrm{MHz}\right): \delta 7.87(3 \mathrm{H}, \mathrm{d}, J=8.7 \mathrm{~Hz}), 7.74(1 \mathrm{H}, \mathrm{s}), 6.86(3 \mathrm{H}, \mathrm{d}, J=8.7 \mathrm{~Hz}), 3.86$ $(2 \mathrm{H}, \mathrm{s}), 3.47(4 \mathrm{H}, \mathrm{s}), 2.77(4 \mathrm{H}, \mathrm{s}), 2.54(3 \mathrm{H}, \mathrm{s}), 2.52(3 \mathrm{H}, \mathrm{s}) .{ }^{13} \mathrm{C} \mathrm{NMR}\left(\mathrm{CDCl}_{3}, 75 \mathrm{MHz}\right): \delta$ 196.6, 196.4, 162.3, 153.6, 130.4, 130.3 (x2), 129.4, 129.1, 128.2, 120.5, 116.0, 113.8 (x2), 61.0, $52.0(\mathrm{x} 2), 47.2(\mathrm{x} 2), 26.2,26.1 . \mathrm{FABMS}, \mathrm{m} / z$ (\% rel. intensity): $353(100)[\mathrm{M}+\mathrm{H}]^{+}, 352$ (76), 351 (39), 205 (27), 204 (15), 203 (26), 177 (14), 174 (11), 162 (23), 154 (13), 149 (37), 148 (12), 136 (11).HRFABMS $m / z$ calcd for $\mathrm{C}_{21} \mathrm{H}_{25} \mathrm{O}_{3} \mathrm{~N}_{2}, 353.1865$; found, 353.1866. Elemental Analysis: calcd C, 71.57; H, 6.86; N, 7.95; found, C, 71.08; H, 6.88; N, 7.80.

\subsubsection{1-(4-(4-(5-Acetyl-2-hydroxy-3-methoxybenzyl)piperazin-1-} yl)phenyl)ethanone (2a)—Compound $2(8.3 \mathrm{~g}, 50 \mathrm{mmol})$, paraformaldehyde (1.5 g, 50 $\mathrm{mmol})$ and 4-piperizinoacetophenone $(10.2 \mathrm{~g}, 50 \mathrm{mmol})$ were treated as described above. The crude product was purified by CC eluting with (i-Pr) ${ }_{2} \mathrm{O} / \mathrm{MeOH}(7: 3)$ to yield 2a (colorless crystalline solid, $14.5 \mathrm{~g}, 76 \%$ ), mp 130-132 ${ }^{\circ} \mathrm{C}$. IR (neat) 2831, 1666, 1597, 1516, $1489,1450,1411,1537,1296,1234,1141,1083,1002,956,921,821,752,594,559$ $\mathrm{cm}^{-1} .{ }^{1} \mathrm{H} \mathrm{NMR}\left(\mathrm{CDCl}_{3}, 300 \mathrm{MHz}\right): \delta 7.83(2 \mathrm{H}, \mathrm{d}, J=9.0 \mathrm{~Hz}), 7.44(1 \mathrm{H}, \mathrm{s}), 7.28(1 \mathrm{H}, \mathrm{s})$, $6.83(2 \mathrm{H}, \mathrm{d}, J=9.0 \mathrm{~Hz}), 3.89(3 \mathrm{H}, \mathrm{s}), 3.81(2 \mathrm{H}, \mathrm{s}), 3.36(4 \mathrm{H}, \mathrm{s}), 2.72(4 \mathrm{H}, \mathrm{s}), 2.51(3 \mathrm{H}, \mathrm{s})$, $2.48(3 \mathrm{H}, \mathrm{s}) .{ }^{13} \mathrm{C} \mathrm{NMR}\left(\mathrm{CDCl}_{3}, 75 \mathrm{MHz}\right): \delta 196.4,196.3,153.5,151.8,147.8,130.2(\mathrm{x} 2)$, 128.7, 128.1, 122.5, 119.8, 113.7 (x2), 110.4, 60.7, 55.8, 51.9 (x2), 47.2 (x2), 25.9 (x2). FABMS, $m / z$ (\% rel. intensity): $383(100)[\mathrm{M}+\mathrm{H}]^{+}, 382$ (75), 381 (28), 307 (12), 217 (12), 207 (13), 205 (25), 204 (11), 203 (22), 179 (40), 162 (20), 155 (17), 154 (67), 138 (20), 137 (41), 136 (51), 120 (11), 107 (16), 91 (11), 89 (13), 77 (11).HRFABMS $\mathrm{m} / \mathrm{z}$ calcd for $\mathrm{C}_{22} \mathrm{H}_{27} \mathrm{O}_{4} \mathrm{~N}_{2}$, 383.1971; found, 383.1968. Elemental Analysis: calcd C, 69.09; H, 6.85; N, 7.32; found, C, 68.42; H, 7.07; N, 7.37.

\subsection{General procedure for the synthesis of bichalcones through the piperazine Mannich base linkage}

The general synthetic strategy employed to prepare the bichalcones through the piperazine Mannich base linkage analogs were based on the Claisen-Schmidt condensation. As shown in Scheme 2, a series of 23 bichalcones were prepared by base-catalyzed condensation of substituted Mannich bases of acetophenones with appropriate aldehydes in $\mathrm{MeOH}$. To a stirred reaction mixture at $0{ }^{\circ} \mathrm{C}$ was added a $30 \%$ solution of $\mathrm{KOH}(40 \mathrm{~mL})$ dropwise over $30 \mathrm{~min}$. The reaction mixture was kept at rt for $24 \mathrm{~h}$, then diluted with water and extracted with EtOAc. Pure target compounds were obtained by silica gel column chromatography (cc) of the residue eluting with various solvent mixtures as indicated below. The structures of all the 23 bichalcones through the piperazine Mannich base linkage analogs were established on the basis of IR, ${ }^{1} \mathrm{H},{ }^{13} \mathrm{CNMR}$, FABMS and HRFABMS.

\subsection{1. (E)-1-(4-Hydroxy-3-((4-(4-((E)-3-(pyridin-2-yl)acryloyl)phenyl)piperazin-1- yl)methyl)phenyl)-3-(pyridin-2-yl)prop-2-en-1-one (3)-Compound 1a (704 mg, 2.0 $\mathrm{mmol}$ ) and 2-pyridinecarboxaldehyde (428 $\mathrm{mg}, 4.0 \mathrm{mmol}$ ) were treated as described above. The crude product was purified by CC eluting with hexanes/EtOAc (1:1) to yield $\mathbf{3}$ (pale yellow solid, $680 \mathrm{mg}, 64 \%$ ), $\mathrm{mp} 59-61^{\circ} \mathrm{C}$. IR (neat) $2874,1657,1608,1589,1522,1468$, $1432,1387,1329,1225,1193,1111,1027,993,927,830,782,661,569 \mathrm{~cm}^{-1} .{ }^{1} \mathrm{H}$ NMR (DMSO- $\left.d_{6}, 300 \mathrm{MHz}\right): \delta 8.67(2 \mathrm{H}, \mathrm{s}), 8.14(2 \mathrm{H}, \mathrm{dd}, J=15.3,15.3 \mathrm{~Hz}), 7.99(4 \mathrm{H}, \mathrm{t}, J=5.7$ $\mathrm{Hz}), 7.87(4 \mathrm{H}, \mathrm{s}), 7.66(2 \mathrm{H}, \mathrm{dd}, J=15.3,15.3 \mathrm{~Hz}), 7.41(2 \mathrm{H}, \mathrm{d}, J=3.9 \mathrm{~Hz}), 7.03(3 \mathrm{H}, \mathrm{dd}, J$ $=8.4 \mathrm{~Hz}), 3.75(2 \mathrm{H}, \mathrm{s}), 3.43(4 \mathrm{H}, \mathrm{s}), 2.63(4 \mathrm{H}, \mathrm{s}) .{ }^{13} \mathrm{C} \mathrm{NMR}\left(\mathrm{DMSO}-d_{6}, 75 \mathrm{MHz}\right): \delta 187.3$, $186.5,161.7,153.8,153.1,152.9,149.9$ (x2), 141.8, 141.3, 137.1 (x2), 130.9, 130.6 (x2), $129.9,128.7,126.9,125.3,125.1,124.8,124.6(\mathrm{x} 2), 124.4,123.0,115.5,113.3(\mathrm{x} 2), 57.2$, 51.9 (x2), 46.4 (x2).FABMS, $m / z$ (\% rel. intensity): $531(11)[\mathrm{M}+\mathrm{H}]^{+}, 530$ (8), 481 (1), 460 (1), 437 (1), 391 (4), 307 (10), 294 (14), 292 (10), 291 (8), 251 (9), 239 (13), 238 (19), 210 (4), 207 (5), 195 (5), 194 (5), 180 (6), 167 (9), 155 (25), 154 (100), 152 (9), 149 (17), 139}


(14), 138 (35), 137 (65), 136 (87), 132 (45), 124 (11), 120 (15), 107 (40), 91 (26), 90 (32), 89 (51), 77 (44).

HRFABMS $m / z$ calcd for $\mathrm{C}_{33} \mathrm{H}_{31} \mathrm{O}_{3} \mathrm{~N}_{4}, 531.2396$; found, 531.2397. Elemental Analysis: calcd C, 74.70; H, 5.75; N, 10.56; found, C, 74.52; H, 5.92; N, 10.34 .

\subsection{2. (E)-1-(4-Hydroxy-3-((4-(4-((E)-3-(pyridin-3-yl)acryloyl)phenyl)piperazin-1-} yl)methyl)phenyl)-3-(pyridin-3-yl)prop-2-en-1-one (4)-Compound 1a (704 mg, 2.0 $\mathrm{mmol}$ ) and 3-pyridinecarboxaldehyde (428 $\mathrm{mg}, 4.0 \mathrm{mmol})$ were treated as described above. The crude product was purified by CC eluting with $\mathrm{CHCl}_{3} / \mathrm{MeOH}$ (9:1) to yield 4 (pale yellow solid, $720 \mathrm{mg}, 68 \%$ ), $\mathrm{mp} 69-71{ }^{\circ} \mathrm{C}$. IR (neat) $3420,2835,1654,1600,1527,1419$, $1346,1307,1284,1226,1192,1122,1026,995,925,806,736,702,628 \mathrm{~cm}^{-1} .{ }^{1} \mathrm{H}$ NMR (DMSO- $\left.d_{6}, 300 \mathrm{MHz}\right): \delta 9.00(2 \mathrm{H}, \mathrm{d}, J=4.5 \mathrm{~Hz}), 8.60(2 \mathrm{H}, \mathrm{s}), 8.33(2 \mathrm{H}, \mathrm{d}, J=9.0 \mathrm{~Hz})$, $8.06(2 \mathrm{H}, \mathrm{d}, J=15.9 \mathrm{~Hz}), 8.05(4 \mathrm{H}, \mathrm{m}), 7.70(2 \mathrm{H}, \mathrm{dd}, J=15.6,15.6 \mathrm{~Hz}), 7.48(2 \mathrm{H}, \mathrm{t}, J=3.9$ $\mathrm{Hz}), 7.04(2 \mathrm{H}, \mathrm{d}, J=8.4 \mathrm{~Hz}), 6.93(1 \mathrm{H}, \mathrm{d}, J=9.0 \mathrm{~Hz}), 3.77(2 \mathrm{H}, \mathrm{s}), 3.44(4 \mathrm{H}, \mathrm{s}), 2.64(4 \mathrm{H}$, s). ${ }^{13} \mathrm{C}$ NMR (DMSO- $\left.d_{6}, 75 \mathrm{MHz}\right): \delta 186.7,186.3,161.8,158.5,152.8,149.3,148.6,148.2$, 139.1, 138.2, 137.1, 136.6, 135.0, 132.7, 131.7, 131.3, 130.8 (x2), 128.8, 127.8, 124.9, 124.6, 124.5, 124.4, 116.4, 115.7, 113.9 (x2), 53.6, 50.5 (x2), 43.8 (x2).FABMS, $m / z$ (\% rel. intensity): $531(5)[\mathrm{M}+\mathrm{H}]^{+}, 307$ (35), 289 (18), 280 (8), 165 (8), 156 (9), $155(48), 154$ (100), 153 (11), 152 (15), 150 (6), 139 (21), 138 (59), 137 (98), 136 (96), 124 (15), 121 (13), 120 (23), 108 (15), 107 (45), 106 (13), 105 (14), 91 (25), 90 (31), 89 (43), 77 (34), 65 (12).HRFABMS $m / z$ calcd for $\mathrm{C}_{33} \mathrm{H}_{31} \mathrm{O}_{3} \mathrm{~N}_{4}, 531.2396$; found, 531.2393. Elemental Analysis: calcd C, 74.70; H, 5.75; N, 10.56; found, C, 74.08; H, 5.92; N, 10.34 .

\subsection{3. (E)-3-(Furan-2-yl)-1-(4-(4-(5-((E)-3-(furan-2-yl)acryloyl)-2-} hydroxybenzyl)piperazin-1-yl)phenyl)prop-2-en-1-one (5)—Compound 1a (704 $\mathrm{mg}, 2.0 \mathrm{mmol}$ ) and 2 -furaldehyde $(384 \mathrm{mg}, 4.0 \mathrm{mmol})$ were treated as described above. The crude product was purified by CC eluting with hexanes/EtOAc (7:3) to yield $\mathbf{5}$ (pale yellow solid, $780 \mathrm{mg}, 77 \%$ ), $\mathrm{mp} 169-171{ }^{\circ} \mathrm{C}$. IR (neat) $3417,2920,1651,1600,1550,1527,1473$, 1388, 1350, 1280, 1230, 1192, 1111, 1018, 925, 817, 744, $644 \mathrm{~cm}^{-1} .{ }^{1} \mathrm{H} \mathrm{NMR}\left(\mathrm{CDCl}_{3}, 300\right.$ $\mathrm{MHz}): \delta 8.00(2 \mathrm{H}, \mathrm{d}, J=9.0 \mathrm{~Hz}), 7.94(1 \mathrm{H}, \mathrm{s}), 7.81(1 \mathrm{H}, \mathrm{s}), 7.58(2 \mathrm{H}, \mathrm{dd}, J=15.0,15.0$ $\mathrm{Hz}), 7.51(2 \mathrm{H}, \mathrm{m}), 7.46(2 \mathrm{H}, \mathrm{d}, J=15.6 \mathrm{~Hz}), 6.91(3 \mathrm{H}, \mathrm{d}, J=9.0 \mathrm{~Hz}), 6.68(2 \mathrm{H}, \mathrm{d}, J=4.5$

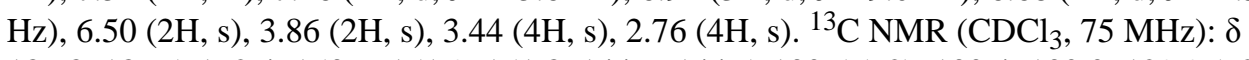
$187.8,187.5,162.4,153.6,151.9,151.8,144.6,144.5,130.5$ (x2), 130.4, 130.0, 129.9 (x2), 129.5, 129.0, 120.8, 119.2, 119.0, 116.2, 115.8, 115.5, 114.0 (x2), 112.6, 112.5, 61.1, 52.1 (x2), 47.3 (x2). FABMS, $m / z$ (\% rel. intensity): 509 (24) $[\mathrm{M}+\mathrm{H}]^{+}, 508$ (11), 307 (27), 289 (14), 283 (9), 240 (7), 227 (7), 155 (36), 154 (100), 153 (9), 152 (13), 147 (8), 139 (17), 138 (42), 137 (82), 136 (100), 135 (11), 124 (11), 121 (23), 120 (18), 115 (9), 108 (10), 107 (33), 106 (11), 105 (12), 91 (24), 90 (26), 89 (30), 78 (12), 77 (23), 73 (20).HRFABMS m/z calcd for $\mathrm{C}_{31} \mathrm{H}_{29} \mathrm{O}_{5} \mathrm{~N}_{2}$, 509.2076; found, 509.2073. Elemental Analysis: calcd C, 73.21; H, 5.55; N, 5.51; found, C, 72.97; H, 5.44; N, 5.32.

\subsection{4. (E)-1-(4-Hydroxy-3-((4-(4-)((E)-3-(thiophen-2-}

yl)acryloyl)phenyl)piperazin-1-yl)methyl)phenyl)-3-(thiophen-2-yl)prop-2-en-1one (6)-Compound 1a (704 mg, $2.0 \mathrm{mmol}$ ) and 2-thiophenecarboxaldehyde (448 mg, 4.0 $\mathrm{mmol}$ ) were treated as described above. The crude product was purified by CC eluting with hexanes/EtOAc (1:1) to yield 6 (pale yellow solid, $750 \mathrm{mg}, 69 \%$ ), mp $126-128{ }^{\circ} \mathrm{C}$. IR (neat) 2874, 1648, 1600, 1511, 1450, 1426, 1365, 1285, 1232, 1190, 1125, 1105, 1028, 998, 925, 817, 708, 657, $566 \mathrm{~cm}^{-1} .{ }^{1} \mathrm{H}$ NMR $\left(\mathrm{CDCl}_{3}, 300 \mathrm{MHz}\right): \delta 7.97(2 \mathrm{H}, \mathrm{d}, \mathrm{J}=9.0 \mathrm{~Hz}), 7.86(2 \mathrm{H}$, d, J = 15.0 Hz), $7.75(2 \mathrm{H}, \mathrm{s}), 7.35(2 \mathrm{H}, \mathrm{d}, \mathrm{J}=15.0 \mathrm{~Hz}), 7.32(3 \mathrm{H}, \mathrm{m}), 7.07(2 \mathrm{H}, \mathrm{s}), 6.91(4 \mathrm{H}$, $\mathrm{d}, \mathrm{J}=8.1 \mathrm{~Hz}), 3.87(2 \mathrm{H}, \mathrm{s}), 3.45(4 \mathrm{H}, \mathrm{s}), 2.78(4 \mathrm{H}, \mathrm{s}) .{ }^{13} \mathrm{C} \mathrm{NMR}\left(\mathrm{CDCl}_{3}, 75 \mathrm{MHz}\right): \delta 187.4$ (x2), 153.5, 140.6, 140.5, 136.3, 135.8, 131.7, 131.5, 130.5 (x3), 130.3, 129.8, 129.4, 128.8, 128.4, 128.2 (x2), 128.1 (x2), 120.6, 120.4, 113.9 (x3), 61.0, 52.0 (x2), 47.2 (x2).FABMS, 
$\mathrm{m} / \mathrm{z}$ (\% rel. intensity): $541(12)[\mathrm{M}+\mathrm{H}]^{+}, 540$ (9), 523 (2), 505 (3), 447 (21), 446 (12), 431 (8), 391 (6), 300 (6), 299 (20), 297 (16), 281 (11), 256 (17), 255 (5), 243 (11), 242 (12), 221 (12), 217 (11), 207 (15), 189 (13), 167 (15), 165 (16), 155 (20), 154 (67), 152 (19), 150 (14), 149 (48), 137 (66), 136 (84), 115 (23), 111 (18), 107 (46), 97 (34), 95 (50), 91 (67), 90 (42), 89 (51), 81 (59), 73 (100), 71 (40), 67 (45), 55 (87).HRFABMS $\mathrm{m} / \mathrm{z}$ calcd for $\mathrm{C}_{31} \mathrm{H}_{29} \mathrm{O}_{3} \mathrm{~N}_{2} \mathrm{~S}_{2}, 541.1620$; found, 541.1617. Elemental Analysis: calcd C, 68.86; H, 5.22; N, 5.18; S, 11.86; found, C, 68.36; H, 5.52; N, 5.45; S, 11.15 .

4.3.5. (E)-1-(4-Hydroxy-3-((4-(4-((E)-3-(3-methylthiophen-2-yl)acryloyl)phenyl)piperazin-1-yl)methyl)phenyl)-3-(3-methylthiophen-2-yl)prop-2-en-1-one (7)Compound 1a (704 mg, $2.0 \mathrm{mmol}$ ) and 3-methyl-2-thiophenecarboxaldehyde (504 mg, 4.0 $\mathrm{mmol}$ ) were treated as described above. The crude product was purified by $\mathrm{CC}$ eluting with hexanes/EtOAc (7:3) to yield 7 (pale yellow solid, $860 \mathrm{mg}, 76 \%$ ), mp 179-181 ${ }^{\circ} \mathrm{C}$. IR (neat) $2875,1648,1600,1516,1493,1452,1384,1288,1220,1189,1110,1034,926,820,752$, $629 \mathrm{~cm}^{-1} .{ }^{1} \mathrm{H}$ NMR $\left(\mathrm{CDCl}_{3}, 300 \mathrm{MHz}\right): \delta 8.04(1 \mathrm{H}, \mathrm{d}, J=3.9 \mathrm{~Hz}), 7.97(2 \mathrm{H}, \mathrm{d}, J=15.0$ $\mathrm{Hz}), 7.96(2 \mathrm{H}, \mathrm{d}, J=9.0 \mathrm{~Hz}), 7.81(1 \mathrm{H}, \mathrm{s}), 7.29(2 \mathrm{H}, \mathrm{d}, J=9.0 \mathrm{~Hz}), 7.28(2 \mathrm{H}, \mathrm{d}, J=15.0$ $\mathrm{Hz}), 6.90(5 \mathrm{H}, \mathrm{m}), 3.90(2 \mathrm{H}, \mathrm{s}), 3.46(4 \mathrm{H}, \mathrm{s}), 2.80(4 \mathrm{H}, \mathrm{s}), 2.38(6 \mathrm{H}, \mathrm{s}) .{ }^{13} \mathrm{C} \mathrm{NMR}\left(\mathrm{CDCl}_{3}\right.$, $75 \mathrm{MHz}): \delta$ 187.8, 187.5, 162.2, 153.4, 142.3, 142.0, 134.7 (x2), 134.5, 134.3, 131.3 (x2), 130.4 (x2), 130.3, 130.0, 129.9, 129.0, 126.6, 120.5, 119.6, 119.4, 116.2, 113.9 (x2), 60.8, 52.0 (x2), 47.1 (x2), 14.2 (x2). FABMS, $m / z$ (\% rel. intensity): 569 (29) $[\mathrm{M}+\mathrm{H}]^{+}, 568(18)$, 553 (2), 461 (2), 445 (10), 313 (23), 312 (9), 311 (20), 309 (8), 307 (10), 281 (11), 270 (17), 258 (11), 257 (17), 207 (15), 189 (12), 165 (10), 155 (23), 154 (89), 152 (19), 151 (54), 149 (18), 147 (30), 138 (30), 137 (56), 136 (100), 107 (41), 105 (24), 91 (36), 90 (36), 89 (48), 77 (48), 73 (78), 71 (19), 69 (31), 57 (38), 55 (38). HRFABMS $m / z$ calcd for $\mathrm{C}_{33} \mathrm{H}_{33} \mathrm{O}_{3} \mathrm{~N}_{2} \mathrm{~S}_{2}$, 569.1933; found, 569.1931. Elemental Analysis: calcd C, 69.69; H, 5.67; N, 4.93; S, 11.58; found, C, 69.48; H, 5.71; N, 4.90; S, 11.46.

4.3.6. (E)-1-(4-Hydroxy-3-((4-(4-((E)-3-(5-methylfuran-2yl)acryloyl)phenyl)piperazin-1-yl)methyl)phenyl)-3-(5-methylfuran-2-yl)prop-2en-1-one (8)-Compound 1a (704 mg, $2.0 \mathrm{mmol}$ ) and 5-methyl-2-furaldehyde (440 mg, $4.0 \mathrm{mmol}$ ) were treated as described above. The crude product was purified by $\mathrm{CC}$ eluting with hexanes/EtOAc (7:3) to yield $\mathbf{8}$ (pale yellow solid, $750 \mathrm{mg}, 70 \%$ ), mp $94-96{ }^{\circ} \mathrm{C}$. IR (neat) 3390, 2873, 1651, 1600, 1527, 1446, 1350, 1222, 1192, 1118, 1022, 802, 732, 671, $617 \mathrm{~cm}^{-1} .{ }^{1} \mathrm{H} \mathrm{NMR}\left(\mathrm{CDCl}_{3}, 300 \mathrm{MHz}\right): \delta 8.01(2 \mathrm{H}, \mathrm{d}, J=9.0 \mathrm{~Hz}), 7.97(1 \mathrm{H}, \mathrm{dd}, J=8.4,2.1$ $\mathrm{Hz}), 7.82(1 \mathrm{H}, \mathrm{d}, J=2.1 \mathrm{~Hz}), 7.53(2 \mathrm{H}, \mathrm{dd}, J=15.3,15.3 \mathrm{~Hz}), 7.38(2 \mathrm{H}, \mathrm{dd}, J=15.3,15.3$ $\mathrm{Hz}), 6.92(2 \mathrm{H}, \mathrm{d}, J=9.0 \mathrm{~Hz}), 6.90(1 \mathrm{H}, \mathrm{d}, J=3.3 \mathrm{~Hz}), 6.59(2 \mathrm{H}, \mathrm{dd}, J=3.3,6.0 \mathrm{~Hz}), 6.12$ $(2 \mathrm{H}, \mathrm{t}, \mathrm{J}=3.3 \mathrm{~Hz}), 3.88(2 \mathrm{H}, \mathrm{s}), 3.57(4 \mathrm{H}, \mathrm{s}), 2.77(4 \mathrm{H}, \mathrm{s}), 2.40(6 \mathrm{H}, \mathrm{s}) .{ }^{13} \mathrm{C} \mathrm{NMR}\left(\mathrm{CDCl}_{3}\right.$, $75 \mathrm{MHz}): \delta 187.8,187.5,162.1,155.5,155.3,153.4,150.5,150.4,130.4$ (x2), 130.2, 130.1, 130.0, 129.7, 129.6, 129.2, 120.7, 117.7, 117.5, 117.4, 117.2, 116.0, $113.9(\mathrm{x} 2), 109.2$, 109.1, 61.1, 52.1 (x2), 47.3 (x2), 13.9 (x2). FABMS, $m / z$ (\% rel. intensity): 537 (61) [M $+\mathrm{H}]^{+}, 536$ (39), 535 (13), 429 (13), 307 (22), 297 (28), 296 (13), 295 (21), 254 (19), 240 (14), 155 (26), 154 (100), 139 (11), 138 (28), 137 (52), 136 (73), 135 (50), 120 (12), 107 (26), 91 (12), 90 (14), 89 (20), 77 (19).HRFABMS $m / z$ calcd for $\mathrm{C}_{33} \mathrm{H}_{33} \mathrm{O}_{5} \mathrm{~N}_{2}, 537.2389$; found, 537.2387. Elemental Analysis: calcd C, 73.86; H, 6.01; N, 5.22; found, C, 73.25; H, $6.08 ; \mathrm{N}, 5.07$.

\subsection{7. (E)-1-(4-Hydroxy-3-((4-(4-)((E)-3-(1-methyl-1H-pyrrol-2-} yl)acryloyl)phenyl)piperazin-1-yl)methyl)phenyl)-3-(1-methyl-1H-pyrrol-2yl)prop-2-en-1-one (9)—Compound $1 \mathbf{a}$ (704 mg, $2.0 \mathrm{mmol}$ ) and N-methylpyrrole-2carboxaldehyde $(436 \mathrm{mg}, 4.0 \mathrm{mmol})$ were treated as described above. The crude product was purified by CC eluting with hexanes/EtOAc (7:3) to yield 9 (pale yellow solid, $780 \mathrm{mg}$, $73 \%), \mathrm{mp} 90-92{ }^{\circ} \mathrm{C}$. IR (neat) 2877, 1642, 1599, 1525, 1480, 1416, 1383, 1336, 1279, 1223, 
1192, 1111, 1059, 1033, 998, 927, 825, 744, 627, 605, $573 \mathrm{~cm}^{-1} .{ }^{1} \mathrm{H}$ NMR (DMS0- $d_{6}, 300$ MHz): $\delta 7.99(2 \mathrm{H}, \mathrm{d}, J=8.4 \mathrm{~Hz}), 7.98(2 \mathrm{H}, \mathrm{s}), 7.65(2 \mathrm{H}, \mathrm{dd}, J=15.0,15.0 \mathrm{~Hz}), 7.51(2 \mathrm{H}, \mathrm{d}$, $J=15.0 \mathrm{~Hz}), 7.02(6 \mathrm{H}, \mathrm{m}), 6.90(1 \mathrm{H}, \mathrm{d}, J=9.0 \mathrm{~Hz}), 6.16(2 \mathrm{H}, \mathrm{d}, J=2.7 \mathrm{~Hz}), 3.76(6 \mathrm{H}, \mathrm{s})$, $3.75(2 \mathrm{H}, \mathrm{s}), 3.40(4 \mathrm{H}, \mathrm{s}), 2.63(4 \mathrm{H}, \mathrm{s}) .{ }^{13} \mathrm{C}$ NMR (DMSO-d 6 , $\left.75 \mathrm{MHz}\right): \delta 186.6,186.0$, $161.1,153.4,131.1,130.5$ (x2), 130.1 (x2), 129.9, 129.8, 129.6, 129.5, 128.2, 128.0, 127.9, 122.6, 116.2, 116.0, 115.3, 113.4 (x2), 112.7, 112.5, 109.2, 109.1, 57.7, 51.9 (x2), 46.7 (x2), 33.9 (x2). FABMS, $m / z$ (\% rel. intensity): 535 (9) $[\mathrm{M}+\mathrm{H}]^{+}, 428$ (7), 307 (5), 296 (22), 295 (9), 294 (21), 253 (19), 241 (13), 240 (25), 239 (14), 189 (18), 155 (16), 154 (68), 153 (13), 149 (17), 147 (14), 137 (47), 136 (68), 134 (100), 133 (18), 131 (10), 121 (13), 120 (20), 107 (42), 106 (37), 105 (19), 91 (34), 90 (34), 89 (54), 81 (24), 78 (32), 77 (62), 73 (54), 71 (16), 69 (19), 65 (23), 63 (23), 57 (34), 55 (35).HRFABMS m/z calcd for $\mathrm{C}_{33} \mathrm{H}_{35} \mathrm{O}_{3} \mathrm{~N}_{4}$, 535.2709; found, 535.2709. Elemental Analysis: calcd C, 74.13; H, 6.41; N, 10.48; found, C, $73.97 ; \mathrm{H}, 6.55 ; \mathrm{N}, 10.14$.

4.3.8. (E)-1-(4-(4-(5-Cinnamoyl-2-hydroxybenzyl)piperazin-1-yl)phenyl)-3phenylprop-2-en-1-one (10)-Compound 1a (704 mg, $2.0 \mathrm{mmol}$ ) and benzaldehyde (424 mg, $4.0 \mathrm{mmol}$ ) were treated as described above. The crude product was purified by CC eluting with hexanes/EtOAc (8:2) to yield 10 (pale yellow solid, $625 \mathrm{mg}, 59 \%$ ), mp 179-181 ${ }^{\circ} \mathrm{C}$. IR (neat) $3414,2831,1651,1600,1527,1492,1446,1346,1280,1226,1188,1033,995$, 925, 825, 767, 736, $694 \mathrm{~cm}^{-1} .{ }^{1} \mathrm{H}$ NMR $\left(\mathrm{CDCl}_{3}, 300 \mathrm{MHz}\right): \delta 8.01(2 \mathrm{H}, \mathrm{d}, J=9.0 \mathrm{~Hz}), 7.96$ $(1 \mathrm{H}, \mathrm{dd}, J=9.0,1.8 \mathrm{~Hz}), 7.80(2 \mathrm{H}, \mathrm{dd}, J=15.6,15.6 \mathrm{~Hz}), 7.82(1 \mathrm{H}, \mathrm{s}), 7.65(4 \mathrm{H}, \mathrm{d}, J=6.0$ $\mathrm{Hz}), 7.55(2 \mathrm{H}, \mathrm{d}, J=15.6 \mathrm{~Hz}), 7.40(6 \mathrm{H}, \mathrm{m}), 6.93(3 \mathrm{H}, \mathrm{d}, J=9.0 \mathrm{~Hz}), 3.88(2 \mathrm{H}, \mathrm{s}), 3.45$ $(4 \mathrm{H}, \mathrm{s}), 2.77$ (4H, s). ${ }^{13} \mathrm{C} \mathrm{NMR}\left(\mathrm{CDCl}_{3}, 75 \mathrm{MHz}\right): \delta 188.4,188.1,162.4,153.6,143.8$, $143.4,135.2,135.0,130.6(\mathrm{x} 2), 130.4,130.3,130.1,129.9,129.0(\mathrm{x} 3), 128.8(\mathrm{x} 2), 128.4$ (x2), 128.3 (x3), 121.8, 121.7, 120.8, 116.2, 114.0 (x2), 61.1, 52.1 (x2), 47.3 (x2). FABMS, $\mathrm{m} / \mathrm{z}$ (\% rel. intensity): 529 (11) $[\mathrm{M}+\mathrm{H}]^{+}, 308$ (8), 307 (33), 293 (7), 289 (19), 189 (5), 178 (5), 166 (7), 165 (11), 156 (9), 155 (47), 154 (100), 153 (11), 152 (16), 139 (22), 138 (58), 137 (98), 136 (92), 131 (14), 124 (16), 121 (22), 120 (24), 115 (10), 108 (15), 107 (46), 105 (16), 91 (27), 90 (32), 89 (43), 79 (12), 77 (37), 65 (12), 63 (11).HRFABMS $m / z$ calcd for $\mathrm{C}_{35} \mathrm{H}_{33} \mathrm{O}_{3} \mathrm{~N}_{2}, 529.2491$; found, 529.2494. Elemental Analysis: calcd C, 9.52; H, 6.10; N, 5.30; found, C, 78.47; H, 6.16; N, 5.04.

\subsection{9. (E)-1-(4-Hydroxy-3-((4-(4-((E)-3-(4-}

methoxyphenyl)acryloyl)phenyl)piperazin-1-yl)methyl)phenyl)-3-(4-

methoxyphenyl)prop-2-en-1-one (11)-Compound $1 \mathbf{a}(704 \mathrm{mg}, 2.0 \mathrm{mmol})$ and 4methoxybenzaldehyde $(544 \mathrm{mg}, 4.0 \mathrm{mmol}$ ) were treated as described above. The crude product was purified by CC eluting with hexanes/EtOAc (7:3) to yield $\mathbf{1 1}$ (pale yellow solid, $720 \mathrm{mg}, 61 \%$ ), $\mathrm{mp} 127-129^{\circ} \mathrm{C}$. IR (neat) 2831, 1647, 1597, 1508, 1450, 1423, 1342, 1292, 1253, 1222, 1172, 1126, 1029, 983, 925, 813, 767, 651, 551, $520 \mathrm{~cm}^{-1} .{ }^{1} \mathrm{H}$ NMR $\left(\mathrm{CDCl}_{3}\right.$, $300 \mathrm{MHz}): \delta 7.99(2 \mathrm{H}, \mathrm{d}, J=9.0 \mathrm{~Hz}), 7.95(1 \mathrm{H}, \mathrm{dd}, J=1.8,9.0 \mathrm{~Hz}), 7.82(1 \mathrm{H}, \mathrm{s}), 7.78(2 \mathrm{H}$, $\mathrm{dd}, J=15.0,15.0 \mathrm{~Hz}), 7.60(4 \mathrm{H}, \mathrm{dd}, J=8.7,8.7 \mathrm{~Hz}), 7.44(2 \mathrm{H}, \mathrm{dd}, J=15.0,15.0 \mathrm{~Hz}), 6.92$ $(7 \mathrm{H}, \mathrm{m}), 3.87(2 \mathrm{H}, \mathrm{s}), 3.84(6 \mathrm{H}, \mathrm{s}), 3.48(4 \mathrm{H}, \mathrm{s}), 2.76(4 \mathrm{H}, \mathrm{s}) .{ }^{13} \mathrm{C} \mathrm{NMR}\left(\mathrm{CDCl}_{3}, 75 \mathrm{MHz}\right)$ : $\delta 188.3,188.1,162.1,161.4,161.3,153.4,143.6,143.1,130.4(x 3), 130.3,130.1,130.0$ (x2), 129.9 (x3), 129.1, 127.8, 127.6, 120.6, 119.4, 119.2, 116.0, 114.2 (x3), 113.9 (x2), 60.9, 55.3 (x2), 52.0 (x2), 47.1 (x2).FABMS, $m / z$ (\% rel. intensity): $589(37)[\mathrm{M}+\mathrm{H}]^{+}, 588$ (17), 472 (34), 471 (100), 470 (47), 455 (21), 337 (16), 324 (14), 323 (53), 322 (17), 321 (42), 320 (14), 319 (12), 307 (15), 280 (41), 267 (20), 266 (26), 189 (19), 161 (61), 155 (15), 154 (67), 151 (13), 149 (34), 137 (32), 136 (53) 133 (19), 107 (19), 105 (10), 91 (13), 90 (14), 89 (18), 77 (20).HRFABMS $\mathrm{m} / z$ calcd for $\mathrm{C}_{37} \mathrm{H}_{37} \mathrm{O}_{5} \mathrm{~N}_{2}, 589.2702$; found, 589.2705. Elemental Analysis: calcd C, 75.49; H, 6.16; N, 4.76; found, C, 74.61; H, 6.19; N, 4.80. 
4.3.10. (E)-3-(Benzo[d][1,3]dioxol-5-yl)-1-(4-(4-(5-((E)-3-(benzo[d][1,3]dioxol-5yl)acryloyl)-2-hydroxybenzyl)piperazin-1-yl)phenyl)prop-2-en-1-one (12)Compound 1a (704 mg, $2.0 \mathrm{mmol}$ ) and 3,4-methylenedioxybenzaldehyde $(600 \mathrm{mg}, 4.0$ $\mathrm{mmol}$ ) were treated as described above. The crude product was purified by $\mathrm{CC}$ eluting with (i- $\mathrm{Pr})_{2} \mathrm{O} / \mathrm{MeOH}(9: 1)$ to yield $\mathbf{1 2}$ (pale yellow solid, $765 \mathrm{mg}, 62 \%$ ), $\mathrm{mp} 83-85^{\circ} \mathrm{C}$. IR (neat) 3005, 2893, 2831, 1654, 1597, 1492, 1446, 1361, 1307, 1249, 1192, 1111, 1037, 991, 929, $810,756,659,601,528 \mathrm{~cm}^{-1} .{ }^{1} \mathrm{H}$ NMR $\left(\mathrm{CDCl}_{3}, 300 \mathrm{MHz}\right): \delta 7.98(2 \mathrm{H}, \mathrm{d}, J=8.7 \mathrm{~Hz}), 7.93$ $(1 \mathrm{H}, \mathrm{dd}, J=2.1,8.7 \mathrm{~Hz}), 7.71(2 \mathrm{H}, \mathrm{dd}, J=15.6,15.6 \mathrm{~Hz}), 7.38(2 \mathrm{H}, \mathrm{d}, J=15.6 \mathrm{~Hz}), 7.14$ $(4 \mathrm{H}, \mathrm{m}), 6.90(2 \mathrm{H}, \mathrm{d}, J=8.7 \mathrm{~Hz}), 6.82(4 \mathrm{H}, \mathrm{m}), 6.00(4 \mathrm{H}, \mathrm{s}), 3.85(2 \mathrm{H}, \mathrm{s}), 3.47(4 \mathrm{H}, \mathrm{s}), 2.74$ $(4 \mathrm{H}, \mathrm{s}) .{ }^{13} \mathrm{C} \mathrm{NMR}\left(\mathrm{CDCl}_{3}, 75 \mathrm{MHz}\right): \delta 188.1,187.8,162.2,153.4,149.6,149.5,148.2$, 143.6, 143.1, 130.4 (x2), 130.2, 130.0, 129.7, 129.5, 129.4, 129.0, 124.9, 124.8, 120.7, 119.8, 119.6, 116.0, 113.9 (x2), 108.5 (x2), 106.5 (x2), 101.4 (x2), 61.0, 52.0 (x2), 47.2 (x2). FABMS, $m / z$ (\% rel. intensity): $617(18)[\mathrm{M}+\mathrm{H}]^{+}, 616(11), 486(17), 485(52), 484$ (32), 483 (15), 337 (33), 335 (22), 307 (22), 294 (21), 281 (15), 280 (14), 189 (12), 175 (30), 165 (16), 155 (24), 154 (100), 152 (11), 149 (28), 138 (27), 137 (49), 136 (75), 135 (12), 120 (14), 107 (27), 91 (15), 90 (17), 89 (27), 77 (22).HRFABMS $m / z$ calcd for $\mathrm{C}_{37} \mathrm{H}_{33} \mathrm{O}_{7} \mathrm{~N}_{2}$, 616.2288; found, 616.2286. Elemental Analysis: calcd C, 72.07; H, 5.23; N, 4.54; found, C, 71.85; H, 5.20; N, 4.52 .

\subsubsection{1. (E)-3-(2-Chlorophenyl)-1-(4-(4-(5-((E)-3-(2-chlorophenyl)acryloyl)-2- hydroxybenzyl)piperazin-1-yl)phenyl)prop-2-en-1-one (13)—Compound 1a (704} $\mathrm{mg}, 2.0 \mathrm{mmol}$ ) and 2-chlorobenzaldehyde $(560 \mathrm{mg}, 4.0 \mathrm{mmol})$ were treated as described above. The crude product was purified by CC eluting with benzene/acetone (9:1) to yield $\mathbf{1 3}$ (pale yellow solid, $680 \mathrm{mg}, 57 \%$ ), $\mathrm{mp} 34-36^{\circ} \mathrm{C}$. IR (neat) 3012, 2831, 1654, 1597, 1442, $1388,1319,1276,1222,1192,1122,1029,995,925,864,825,756,667,570 \mathrm{~cm}^{-1} \cdot{ }^{1} \mathrm{H}$ NMR $\left(\mathrm{CDCl}_{3}, 300 \mathrm{MHz}\right): \delta 8.31(2 \mathrm{H}, \mathrm{dd}, J=15.6,15.6 \mathrm{~Hz}), 7.99(2 \mathrm{H}, \mathrm{d}, J=9.0 \mathrm{~Hz}), 7.94$ $(1 \mathrm{H}, \mathrm{dd}, J=2.1,9.0 \mathrm{~Hz}), 7.80(2 \mathrm{H}, \mathrm{d}, J=15.0 \mathrm{~Hz}), 7.73(2 \mathrm{H}, \mathrm{m}), 7.54(4 \mathrm{H}, \mathrm{m}), 7.31(4 \mathrm{H}$, $\mathrm{m}), 6.91(2 \mathrm{H}, \mathrm{d}, J=9.0 \mathrm{~Hz}), 3.87(2 \mathrm{H}, \mathrm{s}), 3.44(4 \mathrm{H}, \mathrm{s}), 2.76(4 \mathrm{H}, \mathrm{s}) .{ }^{13} \mathrm{C} \mathrm{NMR}\left(\mathrm{CDCl}_{3}, 75\right.$ MHz): $\delta 188.3,187.8,162.5,153.6,139.6,139.1,135.3,135.2,133.5,133.3,131.0,130.9$ (x3), 130.5, 130.2, 130.0, 129.6, 128.6, 127.6 (x3), 127.0, 126.9, 124.6, 124.5, 120.8, 116.1, 113.9 (x2), 61.0, 52.0 (x2), 47.1 (x2).FABMS, $m / z$ (\% rel. intensity): $597(39)[\mathrm{M}+\mathrm{H}]^{+}, 596$ (22), 459 (8), 327 (17), 325 (12), 307 (21), 289 (12), 271 (13), 165 (20), 155 (27), 154 (100), 139 (11), 138 (26), 137 (54), 136 (64), 120 (11), 107 (19), 106 (7), 91 (11), 89 (17), 77 (15).HRFABMS $\mathrm{m} / z$ calcd for $\mathrm{C}_{35} \mathrm{H}_{31} \mathrm{O}_{3} \mathrm{~N}_{2} \mathrm{Cl}_{2}, 597.1712$; found, 597.1714. Elemental Analysis: calcd C, 70.35; H, 5.06; N, 4.69; found, C, 70.03; H, 5.65; N, 4.40.

\subsubsection{2. (E)-3-(2,4-Dichlorophenyl)-1-(4-(4-(5-((E)-3-(2,4-} dichlorophenyl)acryloyl)-2-hydroxybenzyl)piperazin-1-yl)phenyl)prop-2-en-1one (14)—Compound 1a (704 mg, $2.0 \mathrm{mmol}$ ) and 2,4-chlorobenzaldehyde (692 mg, 4.0 $\mathrm{mmol}$ ) were treated as described above. The crude product was purified by CC eluting with benzene/acetone (9:1) to yield $\mathbf{1 4}$ (pale yellow solid, $710 \mathrm{mg}, 53 \%$ ), mp $41-43{ }^{\circ} \mathrm{C}$. IR (neat) 3417, 2843, 2349, 1651, 1597, 1527, 1469, 1384, 1346, 1315, 1222, 1192, 1103, 1049, 995, 925, 813, 732, $671 \mathrm{~cm}^{-1} .{ }^{1} \mathrm{H}$ NMR $\left(\mathrm{CDCl}_{3}, 300 \mathrm{MHz}\right): \delta 8.04(2 \mathrm{H}, \mathrm{dd}, J 15.6,15.6 \mathrm{~Hz})$, $7.99(2 \mathrm{H}, \mathrm{d}, J=9.0 \mathrm{~Hz}), 7.93(1 \mathrm{H}, \mathrm{dd}, J=2.1,9.0 \mathrm{~Hz}), 7.81(1 \mathrm{H}, \mathrm{d}, J=1.8 \mathrm{~Hz}), 7.68(2 \mathrm{H}$, $\mathrm{d}, J=9.0 \mathrm{~Hz}), 7.47(2 \mathrm{H}, \mathrm{dd}, J=15.0,15.0 \mathrm{~Hz}), 7.45(1 \mathrm{H}, \mathrm{s}), 7.36(1 \mathrm{H}, \mathrm{s}), 7.29(2 \mathrm{H}, \mathrm{s}), 6.92$ $(3 \mathrm{H}, \mathrm{d}, J=9.0 \mathrm{~Hz}), 3.89(2 \mathrm{H}, \mathrm{s}), 3.47(4 \mathrm{H}, \mathrm{s}), 2.78(4 \mathrm{H}, \mathrm{s}) .{ }^{13} \mathrm{C} \mathrm{NMR}\left(\mathrm{CDCl}_{3}, 75 \mathrm{MHz}\right): \delta$ 188.0, 187.6, 162.6, 153.7, 138.4, 137.9, 136.2, 136.0, 135.9, 135.8, 132.1, 132.0, 130.7 (x2), 130.6, 130.1, 130.0, 129.5, 128.5, 128.4 (x2), 128.3 (x2), 127.4 (x2), 124.9, 124.8, 120.9, 116.2, 113.9, 61.1, 52.1 (x2), 47 (x2). FABMS, $m / z$ (\% rel. intensity): 667 (13), 666 (10), 665 (11), [M+H] $]^{+}, 307$ (27), 289 (12), 199 (5), 155 (25), 154 (100), 153 (5), 139 (10), 138 (27), 137 (55), 136 (66), 120 (10), 107 (17), 90 (10), 9 (14), 77 (12).HRFABMS m/z 
calcd for $\mathrm{C}_{35} \mathrm{H}_{29} \mathrm{O}_{3} \mathrm{~N}_{2} \mathrm{Cl}_{4}, 665.0932$; found, 665.0929. Elemental Analysis: calcd C, 63.08; $\mathrm{H}, 4.23 ; \mathrm{N}, 4.20$; found, $\mathrm{C}, 62.79 ; \mathrm{H}, 4.44 ; \mathrm{N}, 4.00$.

\subsubsection{3. (E)-1-(4-Hydroxy-3-methoxy-5-((4-(4-((E)-3-(thiophen-2-} yl)acryloyl)phenyl)piperazin-1-yl)methyl)phenyl)-3-(thiophen-2-yl)prop-2-en-1one (15)-Compound $\mathbf{2 a}(955 \mathrm{mg}, 2.5 \mathrm{mmol}$ ) and 2-thiophenecarboxaldehyde (560 mg, $5.0 \mathrm{mmol}$ ) were treated as described above. The crude product was purified by $\mathrm{CC}$ eluting with (i-Pr) ${ }_{2} \mathrm{O} / \mathrm{MeOH}(9: 1)$ to yield $\mathbf{1 5}$ (pale yellow solid, $1.02 \mathrm{gm}, 72 \%$ ), mp $109-111^{\circ} \mathrm{C}$. IR (neat) 3082, 2831, 1647, 1597, 1523, 1454, 1419, 1350, 1288, 1226, 1192, 1165, 1033, 999, 968, 921, 817, 709, $567 \mathrm{~cm}^{-1} .{ }^{1} \mathrm{H}$ NMR (CDCl $\left.3,300 \mathrm{MHz}\right): \delta 7.99(2 \mathrm{H}, \mathrm{d}, J=9.0 \mathrm{~Hz})$, $7.91(2 \mathrm{H}, \mathrm{dd}, J=15.3,15.3 \mathrm{~Hz}), 7.57(1 \mathrm{H}, \mathrm{s}), 7.39(3 \mathrm{H}, \mathrm{m}), 7.33(2 \mathrm{H}, \mathrm{dd}, J=15.3,15.3$ $\mathrm{Hz}), 7.32(2 \mathrm{H}, \mathrm{d}, J=3.6 \mathrm{~Hz}), 7.06(2 \mathrm{H}, \mathrm{d}, J=4.2 \mathrm{~Hz}), 6.91(2 \mathrm{H}, \mathrm{d}, J=9.0 \mathrm{~Hz}), 3.97(3 \mathrm{H}$, s), $3.94(2 \mathrm{H}, \mathrm{s}), 3.44(4 \mathrm{H}, \mathrm{s}), 2.78(4 \mathrm{H}, \mathrm{s}) .{ }^{13} \mathrm{C} \mathrm{NMR}\left(\mathrm{CDCl}_{3}, 75 \mathrm{MHz}\right): \delta 187.5,187.3$, $153.4,151.9,148.1,140.5,140.4,136.2,135.7,131.7,131.4,130.4$ (x2), 129.5, 128.7, $128.3,128.2,128.1$ (x2), 122.4, 120.5, 120.1, 119.9, 113.8 (x2), 110.8, 60.8, 55.9, 51.9 (x2), 47.1 (x2). FABMS, $m / z$ (\% rel. intensity): $571(24)[\mathrm{M}+\mathrm{H}]^{+}, 570$ (15), 477 (20), 476 (13), 307 (25), 299 (13), 297 (11), 289 (15), 273 (11), 256 (11), 155 (25), 154 (100), 139 (11), 138 (29), 137 (61), 136 (70), 120 (11), 107 (20), 91 (11), 90 (13), 89 (18), 77

(16).HRFABMS $m / z$ calcd for $\mathrm{C}_{32} \mathrm{H}_{31} \mathrm{O}_{4} \mathrm{~N}_{2} \mathrm{~S}_{2}, 571.1725$; found, 571.1726. Elemental Analysis: calcd C, 67.34; H, 5.30; N, 4.91; S, 11.24; found, C, 66.75; H, 5.38; N, 4.90; S, 10.76 .

\subsubsection{4. (E)-1-(4-Hydroxy-3-methoxy-5-((4-(4-((E)-3-(3-methylthiophen-2- yl)acryloyl)phenyl)piperazin-1-yl)methyl)phenyl)-3-(3-methylthiophen-2- yl)prop-2-en-1-one (16)—Compound $2 \mathbf{2}(955 \mathrm{mg}, 2.5 \mathrm{mmol})$ and 3-methyl-2-} thiophenecarboxaldehyde $(630 \mathrm{mg}, 5.0 \mathrm{mmol})$ were treated as described above. The crude product was purified by CC eluting with benzene/acetone (9:1) to yield $\mathbf{1 6}$ (pale yellow solid, $975 \mathrm{gm}, 65 \%$ ), $\mathrm{mp} 76-78^{\circ} \mathrm{C}$. IR (neat) 2831, 1647, 1597, 1523, 1450, 1388, 1346, 1288, 1222, 1188, 1037, 825, 752, $524 \mathrm{~cm}^{-1} .{ }^{1} \mathrm{H}$ NMR (DMS0- $\left.d_{6}, 300 \mathrm{MHz}\right): \delta 7.96(2 \mathrm{H}, \mathrm{d}$, $J=9.0 \mathrm{~Hz}), 7.86(2 \mathrm{H}, \mathrm{dd}, J=15.3,15.3 \mathrm{~Hz}), 7.65(3 \mathrm{H}, \mathrm{m}), 7.53(1 \mathrm{H}, \mathrm{s}), 7.40(2 \mathrm{H}, \mathrm{dd}, J=$ 15.0, $15.0 \mathrm{~Hz}), 7.02(4 \mathrm{H}, \mathrm{m}), 3.88(3 \mathrm{H}, \mathrm{s}), 3.79(2 \mathrm{H}, \mathrm{s}), 3.42(4 \mathrm{H}, \mathrm{s}), 2.64(4 \mathrm{H}, \mathrm{s}), 2.36(6 \mathrm{H}$, s). ${ }^{13} \mathrm{C}$ NMR (DMSO- $d_{6}, 75 \mathrm{MHz}$ ): $\delta 186.3,185.7,153.4,151.1,147.4,141.8,141.6,133.9$, 133.8, 133.6, 133.1, 131.2 (x2), 130.0 (x2), 128.5, 127.6, 127.4, 127.3, 123.1, 121.4, 119.3, 119.2, 113.3 (x2), 110.1, 58.1, 55.6, $51.6(\mathrm{x} 2), 46.4$ (x2), $13.8(\mathrm{x} 2)$. FABMS, $m / z$ (\% rel. intensity): 599 (87) [M+H] $]^{+}, 598$ (55), 597 (22), 475 (22), 394 (29), 393 (49), 391 (35), 323 (20), 322 (68), 313 (38), 311 (33), 307 (16), 289 (15), 288 (13), 287 (34), 270 (29), 189 (20), 154 (100), 151 (66), 149 (93), 137 (58), 123 (18), 113 (16), 109 (24), 108 (11), 107 (34), 95 (39), 91 (41), 83 (33), 81 (38), 77 (33), 69 (44).HRFABMS $m / z$ calcd for $\mathrm{C}_{34} \mathrm{H}_{35} \mathrm{O}_{4} \mathrm{~N}_{2} \mathrm{~S}_{2}$, 599.2038; found, 599.2038. Elemental Analysis: calcd C, 68.20; H, 5.72; N, 4.68; S, 10.7; found, C, 67.86; H, 6.03; N, 4.34; S, 10.65 .

4.3.15. (E)-1-(4-(4-(5-Cinnamoyl-2-hydroxy-3-methoxybenzyl)piperazin-1yl)phenyl)-3-phenylprop-2-en-1-one (17)-Compound 2a (955 mg, $2.5 \mathrm{mmol}$ ) and benzaldehyde $(530 \mathrm{mg}, 5.0 \mathrm{mmol}$ ) were treated as described above. The crude product was purified by $\mathrm{CC}$ eluting with (i-Pr) $)_{2} \mathrm{O} / \mathrm{MeOH}(9: 1)$ to yield $\mathbf{1 5}$ (pale yellow solid, $820 \mathrm{mg}$, $59 \%$ ), mp $43-45^{\circ} \mathrm{C}$. IR (neat) $3437,2873,1651,1600,1527,1492,1450,1350,1222,1192$, $1103,999,925,806,767,690,675,563 \mathrm{~cm}^{-1} .{ }^{1} \mathrm{H} \mathrm{NMR}\left(\mathrm{CDCl}_{3}, 300 \mathrm{MHz}\right): \delta 8.01(2 \mathrm{H}, \mathrm{d}, J$ $=9.0 \mathrm{~Hz}), 7.81(2 \mathrm{H}, \mathrm{dd}, J=15.0,15.0 \mathrm{~Hz}), 7.65(5 \mathrm{H}, \mathrm{m}), 7.56(2 \mathrm{H}, \mathrm{dd}, J=15.0,15.0 \mathrm{~Hz})$, $7.42(7 \mathrm{H}, \mathrm{m}), 6.92(2 \mathrm{H}, \mathrm{d}, J=9.0 \mathrm{~Hz}), 3.98(3 \mathrm{H}, \mathrm{s}), 3.90(2 \mathrm{H}, \mathrm{s}), 3.45(4 \mathrm{H}, \mathrm{s}), 2.77(4 \mathrm{H}$, s). ${ }^{13} \mathrm{C}$ NMR (DMSO- $\left.d_{6}, 75 \mathrm{MHz}\right): \delta 188.2,188.0,153.5,152.0,148.2,143.8,143.3,135.1$, 135.0, 130.6 (x2), 130.3, 130.1, 129.6, 128.8 (x4), 128.3 (x2), 128.2 (x3), 122.6, 121.8, $121.5,120.0,113.9(\mathrm{x} 2), 111.0,60.8,56.0,52.0(\mathrm{x} 2), 47.2(\mathrm{x} 2)$. FABMS, $m / z(\% \mathrm{rel}$. 
intensity): 559 (72) [M+H] $]^{+}, 558$ (46), 557 (17), 455 (13), 396 (23), 307 (18), 295 (12), 293 (36), 292 (13), 291 (29), 290 (11), 289 (19), 267 (40), 189 (13), 174 (19), 155 (24), 154 (100), 152 (13), 138 (28), 136 (78), 131 (73), 121 (20), 107 (29), 106 (10), 105 (15), 91 (24), 77 (32).HRFABMS $m / z$ calcd for $\mathrm{C}_{36} \mathrm{H}_{35} \mathrm{O}_{4} \mathrm{~N}_{2}, 559.2597$; found, 559.2600. Elemental Analysis: calcd C, 77.40; H, 6.13; N, 5.01; found, C, 76.81; H, 6.36; N, 4.67.

\subsubsection{6. (E)-1-(4-Hydroxy-3-methoxy-5-((4-(4-((E)-3-(4-} methoxyphenyl)acryloyl)phenyl)piperazin-1-yl)methyl)phenyl)-3-(4methoxyphenyl)prop-2-en-1-one (18)-Compound 2a (955 mg, $2.5 \mathrm{mmol})$ and 4methoxybenzaldehyde $(680 \mathrm{mg}, 5.0 \mathrm{mmol})$ were treated as described above. The crude product was purified by CC eluting with benzene/acetone (9:1) to yield $\mathbf{1 8}$ (pale yellow solid, $1.08 \mathrm{gm}, 70 \%$ ), $\mathrm{mp} 89-91{ }^{\circ} \mathrm{C}$. IR (neat) $2931,2835,1651,1597,1512,1454,1419$, $1388,1346,1300,1257,1168,1111,1029,995,925,821,756,671,528 \mathrm{~cm}^{-1} .{ }^{1} \mathrm{H}$ NMR (DMS0- $\left.d_{6}, 300 \mathrm{MHz}\right): \delta 7.97(2 \mathrm{H}, \mathrm{d}, J=9.0 \mathrm{~Hz}), 7.72(2 \mathrm{H}, \mathrm{dd}, J=15.6,15.6 \mathrm{~Hz}), 7.59$ $(2 \mathrm{H}, \mathrm{d}, J=15.6 \mathrm{~Hz}), 7.56(3 \mathrm{H}, \mathrm{m}), 7.42(3 \mathrm{H}, \mathrm{m}), 6.90(6 \mathrm{H}, \mathrm{m}), 3.95(3 \mathrm{H}, \mathrm{s}), 3.82(8 \mathrm{H}, \mathrm{s})$, $3.41(4 \mathrm{H}, \mathrm{s}), 2.75(4 \mathrm{H}, \mathrm{s}) .{ }^{13} \mathrm{C}$ NMR (DMSO- $\left.d_{6}, 75 \mathrm{MHz}\right): \delta 188.2,188.0,161.4,161.2$, 153.3, 151.7, 148.0, 143.6, 143.1, 130.4 (x2), 130.0 (x2), 129.9 (x2), 129.1, 127.8, 127.6, 122.3, 119.9, 119.4, 119.0, 114.2 (x5), 113.9 (x2), 110.9, 60.9, 56.0, $55.2(\mathrm{x} 2), 52.0(\mathrm{x} 2)$, 47.2 (x2). FABMS, $m / z$ (\% rel. intensity): $619(44)[\mathrm{M}+\mathrm{H}]^{+}, 618$ (29), 617 (11), 323 (17), 322 (6), 321 (15), 307 (24), 298 (5), 297 (14), 293 (4), 289 (12), 280 (13), 161 (32), 155 (24), 154 (100), 153 (6), 152 (8), 139 (9), 138 (25), 137 (52), 136 (67), 121 (9), 120 (10), 107 (18), 91 (10), 90 (12), 89 (17), 77 (15).HRFABMS m/z calcd for $\mathrm{C}_{38} \mathrm{H}_{39} \mathrm{O}_{6} \mathrm{~N}_{2}$, 619.2808; found, 619.2808. Elemental Analysis: calcd C, 73.77; H, 6.19; N, 4.53; found, C, $73.21 ; \mathrm{H}, 6.37 ; \mathrm{N}, 4.44$.

\subsubsection{7. (E)-3-(2-Chlorophenyl)-1-(4-(4-(5-((E)-3-(2-chlorophenyl)acryloyl)-2-} hydroxy-3-methoxybenzyl)piperazin-1-yl)phenyl)prop-2-en-1-one (19)-

Compound 2a (955 mg, $2.5 \mathrm{mmol}$ ) and 2-chlorobenzaldehyde ( $700 \mathrm{mg}, 5.0 \mathrm{mmol})$ were treated as described above. The crude product was purified by CC eluting with benzene/ acetone (9:1) to yield $\mathbf{2 0}$ (pale yellow solid, $925 \mathrm{gm}, 59 \%$ ), mp $42-44{ }^{\circ} \mathrm{C}$. IR (neat) 2873 , $1654,1593,1450,1350,1292,1222,1192,1168,1107,1053,999,921,759,671,570$ $\mathrm{cm}^{-1} .{ }^{1} \mathrm{H} \mathrm{NMR}\left(\mathrm{CDCl}_{3}, 300 \mathrm{MHz}\right): \delta 8.13(2 \mathrm{H}, \mathrm{d}, J=15.6 \mathrm{~Hz}), 7.97(2 \mathrm{H}, \mathrm{d}, J=9.0 \mathrm{~Hz})$, $7.73(2 \mathrm{H}, \mathrm{m}), 7.57(1 \mathrm{H}, \mathrm{d}, J=1.8 \mathrm{~Hz}), 7.50(2 \mathrm{H}, \mathrm{dd}, J=15.3,15.3 \mathrm{~Hz}), 7.47(3 \mathrm{H}, \mathrm{m}), 7.32$ $(4 \mathrm{H}, \mathrm{m}), 6.90(2 \mathrm{H}, \mathrm{d}, J=9.0 \mathrm{~Hz}), 3.96(3 \mathrm{H}, \mathrm{s}), 3.85(2 \mathrm{H}, \mathrm{s}), 3.44(4 \mathrm{H}, \mathrm{s}), 2.78(4 \mathrm{H}, \mathrm{s}) .{ }^{13} \mathrm{C}$ NMR $\left(\mathrm{CDCl}_{3}, 75 \mathrm{MHz}\right): \delta 188.3,187.8,153.5,152.1,148.2,139.6,139.0,135.2,133.5$, 133.3, 130.9, 130.7 (x3), 130.1, 129.3 (x2), 127.6 (x3), 127.0, 126.9, 124.6, 124.5, 122.8, 120.0, 113.9 (x3), 111.1, 60.9, 56.0, 52.0 (x2), 47.2 (x2). FABMS, $\mathrm{m} / z$ (\% rel. intensity): 627 (37) $[\mathrm{M}+\mathrm{H}]^{+}, 626(23), 329$ (10), 327 (20), 325 (16), 307 (18), 301 (20), 289 (12), 284 (12), 167 (11), 165 (29), 155 (27), 154 (100), 139 (13), 138 (30), 137 (61), 136 (74), 120 (14), 107 (23), 105 (10), 91 (15), 90 (14), 89 (20), 77 (17).HRFABMS $\mathrm{m} / z$ calcd for $\mathrm{C}_{36} \mathrm{H}_{33} \mathrm{O}_{4} \mathrm{~N}_{2} \mathrm{Cl}_{2}, 627.1817$; found, 627.1815. Elemental Analysis: calcd C, 68.09; H, 5.14; $\mathrm{N}, 4.46$; found, C, 67.87; H, 5.27; N, 4.34.

\subsubsection{8. (E)-1-(4-Hydroxy-3-methoxy-5-((4-(4-((E)-3-(pyridin-2-} yl)acryloyl)phenyl)piperazin-1-yl)methyl)phenyl)-3-(pyridin-2-yl)prop-2-en-1one (20)-Compound 2a (955 mg, $2.5 \mathrm{mmol}$ ) and 2-pyridinecarboxaldehyde (535 mg, 5.0 $\mathrm{mmol}$ ) were treated as described above. The crude product was purified by CC eluting with benzene/acetone (9:1) to yield $\mathbf{1 9}$ (pale yellow solid, $1.02 \mathrm{gm}, 73 \%$ ), $\mathrm{mp} 84-86{ }^{\circ} \mathrm{C}$. IR (neat) $2831,1658,1589,1527,1492,1465,1431,1330,1222,1192,1165,995,921,783,748,667$ $\mathrm{cm}^{-1} .{ }^{1} \mathrm{H} \mathrm{NMR}\left(\mathrm{CDCl}_{3}, 300 \mathrm{MHz}\right): \delta 8.66(2 \mathrm{H}, \mathrm{t}, J=4.2 \mathrm{~Hz}), 8.14(1 \mathrm{H}, \mathrm{d}, J=3.0 \mathrm{~Hz}), 8.06$ $(2 \mathrm{H}, \mathrm{d}, J=16.2 \mathrm{~Hz}), 8.05(1 \mathrm{H}, \mathrm{d}, J=4.2 \mathrm{~Hz}), 7.75(1 \mathrm{H}, \mathrm{d}, J=15.6 \mathrm{~Hz}), 7.73(1 \mathrm{H}, \mathrm{d}, J=$ $15.6 \mathrm{~Hz}), 7.68(2 \mathrm{H}, \mathrm{d}, J=1.2 \mathrm{~Hz}), 7.62(1 \mathrm{H}, \mathrm{s}), 7.52(1 \mathrm{H}, \mathrm{s}), 7.45(2 \mathrm{H}, \mathrm{m}), 7.28(2 \mathrm{H}, \mathrm{m})$, 
$6.89(2 \mathrm{H}, \mathrm{d}, J=9.0 \mathrm{~Hz}), 3.96(3 \mathrm{H}, \mathrm{s}), 3.87(2 \mathrm{H}, \mathrm{s}), 3.44(4 \mathrm{H}, \mathrm{s}), 2.76(4 \mathrm{H}, \mathrm{s}) .{ }^{13} \mathrm{C} \mathrm{NMR}$ $\left(\mathrm{CDCl}_{3}, 75 \mathrm{MHz}\right): \delta 187.9,187.8,153.5,153.3,153.1,152.2,149.9$ (x2), 148.1, 141.6, 141.2, 136.8, 136.7, 130.8 (x2), 129.3, 128.4, 125.4 (x2), 125.1, 124.9, 124.1, 124.0, 123.0, 119.9, 113.7 (x2), 110.8, 60.7, 55.9, $51.9(\mathrm{x} 2), 47.0$ (x2). FABMS, $\mathrm{m} / \mathrm{z}$ (\% rel. intensity): $561(77)[\mathrm{M}+\mathrm{H}]^{+}, 560$ (47), 559 (20), 456 (11), 380 (17), 307 (13), 295 (12), 294 (40), 293 (13), 292 (35), 291 (20), 290 (14), 268 (50), 251 (26), 155 (24), 154 (81), 138 (29), 136 (68), 132 (100), 109 (21), 107 (33), 106 (40), 105 (26), 91 (30), 81 (35), 77 (26), 69 (48), 57 (47), 55 (46).HRFABMS $\mathrm{m} / z$ calcd for $\mathrm{C}_{34} \mathrm{H}_{33} \mathrm{O}_{4} \mathrm{~N}_{4}, 561.2502$; found, 561.2501. Elemental Analysis: calcd C, 72.84; H, 5.75; N, 9.99; found, C, 72.40; H, 6.07; N, 9.55.

4.3.19. (E)-1-(3-((4-(4-Acetylphenyl)piperazin-1-yl)methyl)-4-hydroxyphenyl)-3(1H-pyrrol-2-yl)prop-2-en-1-one (21)-Compound 1 (1.36 g, $10 \mathrm{mmol})$ and pyrrole2carboxaldehyde $(950 \mathrm{mg}, 10 \mathrm{mmol})$ were treated as described above for the general procedure for chalcones to obtain $\mathbf{1 b}$ in $82 \%$ yield. The crude product was used directly in the Mannich base reaction. Compound $\mathbf{1 b}(1.065 \mathrm{~g}, 5 \mathrm{mmol})$, 4-piperizinoacetophenone $(1.02 \mathrm{~g}, 5 \mathrm{mmol})$ and paraformaldehyde $(150 \mathrm{mg}, 5 \mathrm{mmol})$ were treated as described above. The crude product was purified by CC eluting with hexanes/EtOAc (7:3) to yield $\mathbf{2 1}$ (pale yellow solid, $1.5 \mathrm{gm}, 70 \%$ ), mp 66-68 ${ }^{\circ} \mathrm{C}$. IR (neat) 1670, 1643, 1597, 1570, 1531, 1450, 1411, 1357, 1284, 1242, 1126, 1029, 975, 821, 752, 686, $605 \mathrm{~cm}^{-1} .{ }^{1} \mathrm{H}$ NMR (DMS0- $d_{6}$, $300 \mathrm{MHz}): \delta 11.64(1 \mathrm{H}, \mathrm{s}, \mathrm{NH}), 7.94(2 \mathrm{H}, \mathrm{d}, J=9.0 \mathrm{~Hz}), 7.79(2 \mathrm{H}, \mathrm{dd}, J=8.1,1.5 \mathrm{~Hz})$, $7.57(1 \mathrm{H}, \mathrm{d}, J=15.3 \mathrm{~Hz}), 7.50(1 \mathrm{H}, \mathrm{d}, J=15.3 \mathrm{~Hz}), 7.09(1 \mathrm{H}, \mathrm{s}), 7.03(2 \mathrm{H}, \mathrm{d}, J=9.0 \mathrm{~Hz})$, $6.87(1 \mathrm{H}, \mathrm{d}, J=8.1 \mathrm{~Hz}), 6.65(1 \mathrm{H}, \mathrm{s}), 6.20(1 \mathrm{H}, \mathrm{s}), 3.70(2 \mathrm{H}, \mathrm{s}), 3.40(4 \mathrm{H}, \mathrm{s}), 2.61(4 \mathrm{H}, \mathrm{s})$, $2.50(3 \mathrm{H}, \mathrm{s}) .{ }^{13} \mathrm{C}$ NMR (DMSO- $\left.d_{6}, 75 \mathrm{MHz}\right): \delta 196.3,186.2,161.3,153.5,132.7,130.5$, 130.0 (x2), 129.6, 129.3, 128.5, 128.0, 123.6, 122.5, 115.5, 115.3, 114.9, 113.5 (x2), 110.4, 57.4, 51.9 (x2), 46.6 (x2), 26.3. FABMS, $m / z$ (\% rel. intensity): $430(11)[\mathrm{M}+\mathrm{H}]^{+}, 307(35)$, 289 (18), 155 (25), 154 (100), 139 (10), 138 (26), 137 (48), 136 (63), 107 (16), 89 (13).HRFABMS $\mathrm{m} / z$ calcd for $\mathrm{C}_{26} \mathrm{H}_{28} \mathrm{O}_{3} \mathrm{~N}_{3}, 430.2131$; found, 430.2130. Elemental Analysis: calcd C, 72.71; H, 6.34; N, 9.78; found, C, 71.94; H, 6.45; N, 9.52.

\subsubsection{0. (E)-1-(3-((4-(4-Acetylphenyl)piperazin-1-yl)methyl)-4-hydroxyphenyl)-3-} (1-methyl-1H-pyrrol-2-yl)prop-2-en-1-one (22)-Compound 1 (1.36 gm, 10 mmols) and $\mathrm{N}$-methyl-pyrrole-2-carboxaldehyde $(1.09 \mathrm{~g}, 10 \mathrm{mmol})$ were treated as described above in the synthesis of chalcones, to obtain $1 \mathrm{c}$ in $79 \%$ yield. The crude product was used directly in the Mannich base reaction. Compound $1 \mathrm{c}(1.14 \mathrm{~g}, 5 \mathrm{mmol})$, 4-piperizinoacetophenone $(1.02 \mathrm{~g}, 5 \mathrm{mmol})$, and paraformaldehyde $(150 \mathrm{mg}, 5 \mathrm{mmol})$ were treated as described above. The crude product was purified by $\mathrm{CC}$ eluting with (i-Pr) ${ }_{2} \mathrm{O} / \mathrm{MeOH}(9: 1)$ to yield $\mathbf{2 2}$ (pale yellow solid, $1.45 \mathrm{gm}, 65 \%$ ), mp 166-168 ${ }^{\circ} \mathrm{C}$. IR (neat) 3390, 2873, 1597, 1527, 1350, 1284, 1192, 1103, 1037, 925, 806, $675 \mathrm{~cm}^{-1} .{ }^{1} \mathrm{H}$ NMR (DMSO- $\left.d_{6}, 300 \mathrm{MHz}\right): \delta 7.99(2 \mathrm{H}, \mathrm{d}$, $J=9.0 \mathrm{~Hz}), 7.83(1 \mathrm{H}, \mathrm{s}), 7.79(1 \mathrm{H}, \mathrm{s}), 7.64(1 \mathrm{H}, \mathrm{d}, J=15.0 \mathrm{~Hz}), 7.51(1 \mathrm{H}, \mathrm{d}, J=15.0 \mathrm{~Hz})$, $7.02(3 \mathrm{H}, \mathrm{d}, J=9.0 \mathrm{~Hz}), 6.99(1 \mathrm{H}, \mathrm{d}, J=3.3 \mathrm{~Hz}), 6.88(1 \mathrm{H}, \mathrm{d}, J=9.0 \mathrm{~Hz}), 6.16(1 \mathrm{H}, \mathrm{t}, J=$ $3.3 \mathrm{~Hz}), 3.76(3 \mathrm{H}, \mathrm{s}), 3.72(2 \mathrm{H}, \mathrm{s}), 3.40(4 \mathrm{H}, \mathrm{s}), 2.62(4 \mathrm{H}, \mathrm{s}), 2.49(3 \mathrm{H}, \mathrm{s}) .{ }^{13} \mathrm{C} \mathrm{NMR}$ (DMSO- $\left.d_{6}, 75 \mathrm{MHz}\right): \delta 196.1,186.0,161.2,153.4,130.5,130.3,130.1(\mathrm{x} 2), 129.8,129.5$, $128.4,128.0,127.8,122.5,116.2,115.1,113.3$ (x2), 112.4, 109.0, 57.3, 51.9 (x2), 46.6 (x2), 33.9, 26.2. FABMS, $m / z$ (\% rel. intensity): 444 (66) $[\mathrm{M}+\mathrm{H}]^{+}, 443$ (35), 442 (15), 337 (12), 307 (21), 296 (12), 294 (13), 289 (11), 253 (12), 239 (13), 155 (25), 149 (24), 139 (11), 138 (28), 137 (53), 136 (71), 134 (40), 120 (14), 107 (25), 106 (14), 90 (15), 89 (21), 77 (19).HRFABMS $\mathrm{m} / z$ calcd for $\mathrm{C}_{27} \mathrm{H}_{30} \mathrm{O}_{3} \mathrm{~N}_{3}$, 444.2287; found, 444.2287. Elemental Analysis: calcd C, 73.11; H, 6.59; N, 9.47; found, C, 72.63; H, 6.69; N, 9.47.

\subsubsection{1. (E)-1-(3-((4-(4-Acetylphenyl)piperazin-1-yl)methyl)-4-hydroxy-5- methoxyphenyl)-3-(pyridin-3-yl)prop-2-en-1-one (23)-Compound 2 (1.66 g, 10} $\mathrm{mmol})$ and 3-pyridinecarboxaldehyde $(1.07 \mathrm{~g}, 10 \mathrm{mmol})$ were treated as described above in 
the general procedure for chalcones to obtain $\mathbf{2 b}$ in $75 \%$ yield. The crude product was used directly in the Mannich base reaction. Compound $2 \mathbf{b}$ (1.28 g, $5.0 \mathrm{mmol}), 4-$

piperizinoacetophenone (1.02 g, $5.0 \mathrm{mmol})$, and paraformaldehyde $(150 \mathrm{mg}, 5.0 \mathrm{mmol})$ were treated as described above. The crude product was purified by CC eluting with (i$\mathrm{Pr})_{2} \mathrm{O} / \mathrm{MeOH}(9: 1)$ to yield 23 (pale yellow solid, $1.45 \mathrm{gm}, 62 \%$ ), mp $146-148{ }^{\circ} \mathrm{C}$. IR (neat) 2831, 1658, 1589, 1489, 1450, 1411, 1357, 1300, 1222, 1192, 1145, 1107, 1083, 999, 921, 806, 752, 678, 628, $563 \mathrm{~cm}^{-1} .{ }^{1} \mathrm{H}$ NMR $\left(\mathrm{CDCl}_{3}, 300 \mathrm{MHz}\right): \delta 8.85(1 \mathrm{H}, \mathrm{s}), 8.60(1 \mathrm{H}, \mathrm{s})$, $7.99(2 \mathrm{H}, \mathrm{d}, J=9.0 \mathrm{~Hz}), 7.93(1 \mathrm{H}, \mathrm{d}, J=7.5 \mathrm{~Hz}), 7.75(1 \mathrm{H}, \mathrm{d}, J=15.6 \mathrm{~Hz}), 7.60(1 \mathrm{H}, \mathrm{d}, J=$ $15.6 \mathrm{~Hz}), 7.47(1 \mathrm{H}, \mathrm{d}, J=1.2 \mathrm{~Hz}), 7.35(1 \mathrm{H}, \mathrm{m}), 7.32(1 \mathrm{H}, \mathrm{s}), 6.91(2 \mathrm{H}, \mathrm{d}, J=9.0 \mathrm{~Hz}), 3.93$ $(3 \mathrm{H}, \mathrm{s}), 3.85(2 \mathrm{H}, \mathrm{s}), 3.45(4 \mathrm{H}, \mathrm{s}), 2.76(4 \mathrm{H}, \mathrm{s}), 2.54(3 \mathrm{H}, \mathrm{s}) .{ }^{13} \mathrm{C} \mathrm{NMR}\left(\mathrm{CDCl}_{3}, 75 \mathrm{MHz}\right): \delta$ 196.5, 187.3, 153.7, 151.9, 150.7, 149.7, 147.9, 139.4, 134.4, 130.7 (x3), 128.8, 128.4, 123.6, 122.6, 119.8, 113.9 (x3), 110.5, 60.9, 56.0, 52.0 (x2), 47.2 (x2), 26.1.FABMS, $m / z(\%$ rel. intensity): 472 (18) [M+H] $]^{+}, 392$ (13), 391 (46), 307 (11), 167 (25), 155 (25), 154 (87), 152 (12), 150 (17), 149 (100), 139 (17), 138 (35), 137 (64), 136 (66), 124 (10), 121 (15), 120 (14), 113 (23), 107 (28), 97 (22), 95 (29), 91 (23), 89 (18), 77 (18), 69 (40), 57 (51), 55 (38).HRFABMS $\mathrm{m} / z$ calcd for $\mathrm{C}_{28} \mathrm{H}_{30} \mathrm{O}_{4} \mathrm{~N}_{3}, 472.2236$; found, 472.2239. Elemental Analysis: calcd C, 71.32; H, 6.20; N, 8.91; found, C, 70.43; H, 6.16; N, 8.74.

\subsection{Measurement of NADPH oxidase activity}

NADPH oxidase activity was measured as described previously. ${ }^{10}$ Test compounds were added to the wells of a bioluminescence plate and incubated with $50 \mu \mathrm{g}$ of cell homogenate for $20 \mathrm{~min}$ at $37^{\circ} \mathrm{C}$ in the dark. $\mathrm{O}_{2}$ production was stimulated with $200 \mu \mathrm{M} \mathrm{NADPH}$, and the chemiluminescence was monitored for $30 \mathrm{~min}$, after which the AUC (area under the curve) was calculated to represent reactive oxygen species production (NADPH activity).

\subsection{Measurement of 1,1-diphenyl-2-picrylhydrazyl (DPPH) radical-scavenging capacity}

The DPPH radical -scavenging capacity assay was performed in our previous report. ${ }^{20}$ The DPPH solution ( $200 \mu \mathrm{L}$, at a final concentration of $200 \mu \mathrm{M}$ in $\mathrm{MeOH}$ ) was added to $10 \mu \mathrm{L}$ of diluted drugs in each well of a 96-well microplate, and the resulting solution was allowed to react for $30 \mathrm{~min}$ in the dark at rt. The absorbance (A517 OD units) is defined as the optical density (OD) measured at $517 \mathrm{~nm}$ caused by the DPPH radical as determined using a Power Wave ${ }^{\mathrm{TM}}$ XS (BioTek) microplate-spectrophotometer. The radical-scavenging capacity is expressed as the change in the $\mathrm{OD}_{517}$ over $30 \mathrm{~min}(\triangle \mathrm{A} 517 \mathrm{OD}$ units/30 min). The antioxidant, Trolox (OXIS, USA), was included as a reference compound.

\subsection{Microglial cell culture and measurement of nitric oxide (NO)}

A murine microglial cell line (BV2) was cultured in Dulbecco's modified Eagle medium (DMEM; Gibco, USA) supplemented with 5\% fetal bovine serum (Hyclone, USA). The production of NO was determined by measuring the accumulation of nitrite in the culture medium $24 \mathrm{~h}$ after stimulation with LPS $(0.5 \mu \mathrm{g} / \mathrm{mL})$ by the Griess reagent as in our previous report. ${ }^{10}$

\subsection{Western immunoblot analysis of iNOS and NFKB p65}

Equal amounts of protein $(50 \mu \mathrm{g})$ at different time points from $0.5 \mu \mathrm{g} / \mathrm{mL}$ LPS-treated samples in the absence or presence of compound $\mathbf{4}$ or $\mathbf{1 1}(0.5 \sim 1.0 \mu \mathrm{M})$ were subjected to sodium dodecylsulfate polyacrylamide gel electrophoresis (SDS-PAGE) and electrotransferred to a hydrophobic polyvinylidene difluoride (PVDF) membrane. After blocking with 5\% nonfat milk in phosphate buffered saline (PBS) containing $0.05 \%$ Tween 20 (PBST) at $4{ }^{\circ} \mathrm{C}$ for $1 \mathrm{~h}$, the membrane was washed three times with PBST and incubated overnight at $4{ }^{\circ} \mathrm{C}$ with an antibody against iNOS (BD Pharmingen, BD Biosciences, San Diego, CA, USA) and NFkB p65 (BD Transduction Laboratories, BD Biosciences, San 
Diego, CA, USA) at a properly titrated dilution (1:1000 2500). After additional washes with PBST, the membrane was incubated with a second antibody IgG conjugated with horseradish peroxidase (Santa Cruz Biotechnology, Santa Cruz, CA, USA) for $1 \mathrm{~h}$ at rt. The immunoblot on the membrane was visible after development with an enhanced chemiluminescence (ECL) system (Perkin-Elmer, Wellesley, MA, USA) and was quantitated using an image program ${ }^{21}$ (Multi Gauge $v 2.2$ software, Fujifilm, Tokyo, Japan).

\subsection{Cytotoxic activity assay}

All stock cultures were grown in T-25 flasks. Freshly trypsinized cell suspensions were seeded in 96-well microtiter plates at densities of 1500-7500 cells per well with compounds added from DMSO-diluted stock. After 3 days in culture, attached cells were fixed with cold $50 \%$ trichloroacetic acid and then stained with $0.4 \%$ sulforhodamine B. The absorbance at $562 \mathrm{~nm}$ was measured using a microplate reader after solubilizing the bound dye. The mean $\mathrm{EC}_{50}$ is the concentration of agent that reduces cell growth by $50 \%$ under the experimental conditions and is the average from at least three independent determinations that were reproducible and statistically significant. The following human tumor cell lines were used in the assay: A549 (non small cell lung cancer), HCT-8 (ileocecal), KB (nasopharyngeal carcinoma) and DU145 (prostate cancer). All cell lines were obtained from the Lineberger Comprehensive Cancer Center (UNC-CH) or from ATCC (Rockville, MD) and were cultured in RPMI-1640 medium supplemented with $25 \mu \mathrm{M}$ HEPES, $0.25 \%$ sodium bicarbonate, and $10 \%$ fetal bovine serum. ${ }^{22}$

\subsection{Cell culture}

Human colon adenocarcinoma cell line HT-29 was obtained from the American Type Culture Collection. Cells were maintained in RPMI-1640 containing $100 \mathrm{M}$ )mL/L FBS with 100,000 U/L penicillin and $100 \mathrm{mg} / \mathrm{L}$ streptomycin.

\subsection{MTT assay}

HT-29 cells were plated onto 96-well plates and exposure to compound $\mathbf{2 3}$ as detailed concentration in respective experiments for 24 and $48 \mathrm{~h}$. Then, MTT was added to each well then incubated for an additional $4 \mathrm{~h}$ in the dark at $37^{\circ} \mathrm{C}$. The medium was then aspirated from the wells and the blue formazon product was dissolved in $100 \mu \mathrm{L}$ of DMSO. The plates were analyzed at O.D.570 $\mathrm{nm}$ using a spectrophotometric plate reader (Bio-Rad, Tokyo, Japan). Each data point was replicated in triplicate. Percentage of cell viability was calculated as (O.D. of drug-treated sample/O.D. of none treated sample) $\times 100 \%$.

\subsection{DAPI staining}

After compound $23(30 \mu \mathrm{M})$ treatment, cells were fixed in $4 \%$ paraformaldehyde for $30 \mathrm{~min}$, and incubated with $1 \mu \mathrm{g} / \mathrm{mL}$ of DAPI staining solution for $30 \mathrm{~min}$ in the dark. The apoptotic cells were observed through fluorescence microscopy (Zeiss, Oberköchen, Germany).

\subsection{Assessment for apoptosis}

The induction of cell apoptosis was assayed by Tdt-mediated deoxyuridine triphosphate nick end labeling (TUNEL) staining. Cells were seeded into each well of 6-well plate. After the compound 23 time-dependent 24 and $48 \mathrm{~h}$ treatments, cells were harvested and were then immediately incubated with working strength terminal deoxynucleotidyl transferase (Tdt) enzyme in a humidified chamber at $37^{\circ} \mathrm{C}$ for $1 \mathrm{~h}$. Cells were immersed in stop/wash buffer and gently rinsed with PBS. FITC-labeled antidigoxigenin conjugate was then applied to cells and incubated at $37^{\circ} \mathrm{C}$ for $30 \mathrm{~min}$ in the dark. Cells were washed with PBS then TUNEL positive cells were determined by flow cytometry (FACSCalibur, Becton Dickinson). 


\subsection{Western blotting}

Proteins $(30 \mu \mathrm{g})$ were resolved on SDS-PAGE and transferred onto a polyvinylidene fluoride membrane (PVDF; Millipore). After blocking, the blots were incubated with an appropriate dilution of specific monoclonal antibodies for Fas/CD95, FADD, cytochrome $c$, Apaf-1, pro-caspase-9, pro-caspase-8, caspase-3, AIF, Endo G, Bax, Bcl-2, t-Bid (Santa Cruz Biotechnology, USA) for $12 \mathrm{~h}$. Blots were washed three times and then incubated with horseradish peroxidase-conjugated secondary antibody (Santa Cruz Biotechnology, USA). The specific protein was detected by using enhanced chemiluminescence kits (Amersham, ECL Kits) (30).

\subsection{Caspase activity assay}

HT-29 cells were collected in lysis buffer (50 mM Tris-HCl, 1 mM EDTA, 10 mM EGTA, $10 \mathrm{mM}$ digitonin and $2 \mathrm{mM}$ DTT) on ice for $10 \mathrm{~min}$. The lysates were centrifuged at $15,000 \times \mathrm{g}$ at $4{ }^{\circ} \mathrm{C}$ for $10 \mathrm{~min}$. Cell lysates $(50 \mu \mathrm{g}$ protein) were incubated with caspase-3, -9 and -8 specific substrates (Ac-DEVD-pNA, Ac-LEHD-pNA, and Ac-IETD-pNA) with reaction buffer in a 96 -well plate at $37^{\circ} \mathrm{C}$ for $1 \mathrm{~h}$. The caspase activity was determined by measuring OD 405 of the released pNA.

\subsection{Statistical analysis}

Student's $t$-test was used to analyze differences between compound $\mathbf{2 3}$ treated and control groups. $* \mathrm{p}<0.05, * * \mathrm{p}<0.01, * * * \mathrm{p}<0.001$

\section{Acknowledgments}

This work was supported by a grant of National Science Council, Taiwan, Republic of China, and Grant No.(OUA 95-3-2-021) from the National Cheng Kung University, Tainan, Taiwan R.O.C awarded to T. S. Wu. Partial support was received from NIH grant CA-17625 awarded to K. H. Lee.

\section{References and notes}

1. Kuo S. Oncogenesis. 1997; 8:47-69.

2. Mukherjee S, Kumar V, Prasad AK, Raj HG, Bracke ME, Olsen CE, Jain SC, Parmar VS. Bioorg. Med. Chem. 2001; 9:337-345. [PubMed: 11249126]

3. Nielsen SF, Larsen MT, Schonning BK, Kromann H. J. Med. Chem. 2005; 48:2667-2677. [PubMed: 15801857]

4. Goker H, Boykin DW, Yildiz S. Bioorg. Med. Chem. 2005; 13:1707-1714. [PubMed: 15698788]

5. Bhat BA, Dhar KL, Puri SC, Saxena AK, Shammuravel M, Qazi GN. Bioorg. Med. Chem. Lett. 2005; 15:3177-3180. [PubMed: 15893928]

6. Boeck P, Falcao CAB, Leal PC, Yunes RA, Filho VC, Terres-Santos EC, Rossi-Bergman B. Bioorg. Med. Chem. 2006; 14:1538-1545. [PubMed: 16386424]

7. Ladislaus KM, Samuel OY, Abegaz BM. J. Nat. Prod. 2003; 66:599-604. [PubMed: 12762790]

8. Reviews: Kleinman EF. Trost BM, Fleming I, Heathcock CH. Comprehensive Organic Synthesis. 1991; 2New York:893.

9. Vijaya Bhaskar Reddy M, Su CH, Chiou WF, Liu YN, Chen RYH, Bastow KF, Lee KH, Wu TS. Bioorg. Med. Chem. 2008; 16:7358-7370. [PubMed: 18602831]

10. Wang YH, Wang WY, Chang CC, Liou KT, Sung YJ, Liao JF, Chen CF, Chang S, Hou YC, Chou YC, Shen YC. J. Biomed. Sci. 2006; 13:127-141. [PubMed: 16283433]

11. Srinivasan B, Johnson TE, Lad R, Xing C. J. Med. Chem. 2009; 52:7228-7235. [PubMed: 19883086]

12. Jin XY, Lee SH, Park PH, Hur J, Kim SA, Kim HS, Sohn DH. Pharmacol. Toxicol. 2010; 106:454-460.

13. Roos WP, Kaina B. Trends Mol. Med. 2006; 12:440-450. [PubMed: 16899408] 
14. Lee JH, Paull TT. Oncogene. 2007; 26:7741-7748. [PubMed: 18066086]

15. Lavrik I, Golka A, Krammer PH. J. Cell Sci. 2005; 118:265-267. [PubMed: 15654015]

16. Dimmock JR, Erciyas E, Kumar P, Hetherington M, Quail JW, Pugazhenthi U, Aspin SA, Hayes SJ, Allen TM, Halleran S, Clercq ED, Balzarini J, Stables JP. Eur. J. Med. Chem. 1997; 32:583594.

17. Kesten SJ, Johnson J, Werbel LM. J. Med. Chem. 1987; 30:906-911. [PubMed: 3553599]

18. Comanita E, Roman G, Popovici I, Comanita B. J. Serb. Chem. Soc. 2001; 66:9-16.

19. Chi KW, Ahn YS, Shim KT, Park TH, Ahn JS. Bull. Korean Chem. Soc. 1999; 20:973-976.

20. Lin LC, Wang YH, Hou YC, Chang S, Liou KT, Chou YC, Wang WY, Shen YC. J. Pharm. Pharmacol. 2006; 58:129-135. [PubMed: 16393473]

21. Wang YH, Shen YC, Liao JF, Lee CH, Chou CY, Liou KT, Chou YC. Br. J. Pharmacol. 2008; 154:1327-1338. [PubMed: 18500357]

22. Wang X, Bastow KF, Sun CM, Lin YL, Yu HJ, Don MJ, Wu TS, Nakamura S, Lee KH. J. Med. Chem. 2004; 47:5816-5819. [PubMed: 15509181] 
control LPS L+ cpd4 L+cpd4

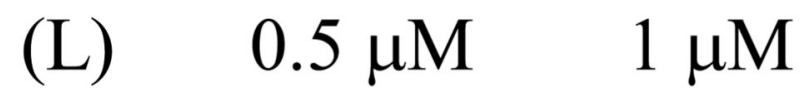

iNOS

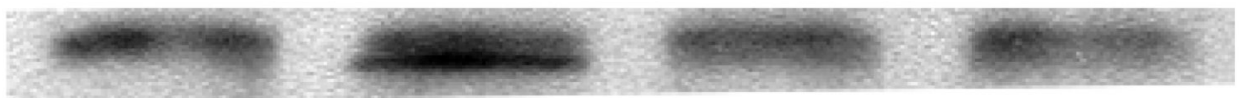
$\mathrm{p} 65(\mathrm{C})$ $\mathrm{p} 65(\mathrm{~N})$ actin

\section{control LPS L+ cpd11 L+cpd11 (L) $\quad 0.5 \mu \mathrm{M} \quad 1 \mu \mathrm{M}$}

iNOS $\mathrm{p} 65(\mathrm{C})$ $\mathrm{p} 65(\mathrm{~N})$ actin

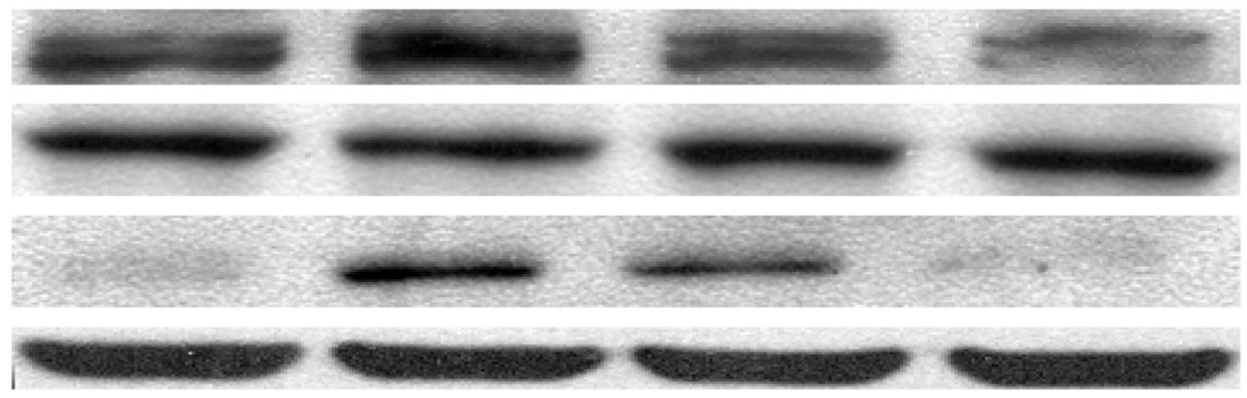

Figure 1.

Effects of compounds $\mathbf{4}$ and $\mathbf{1 1}$ on the LPS-induced iNOS expression and nuclear translocation of NF- $\mathrm{Bp} 65$ in murine microglial cells. Representative immunoblots of iNOS expression and nuclear $(\mathrm{N})$ translocation of NF- $\mathrm{KB}$ p65 [p65(N)] from cytosol $[\mathrm{p} 65(\mathrm{C})]$ in microglial cells receiving water only (control), $0.5 \mu \mathrm{g} / \mathrm{mL}$ LPS (L) for $2 \mathrm{~h}$, or $0.5 \mu \mathrm{g} / \mathrm{mL}$ LPS plus $0.5-1.0 \mu \mathrm{M}$ of compound 4 or $11(\mathrm{~L}+\mathrm{cpd} 4$ or $\mathrm{L}+\mathrm{cpd} 11)$. The $\beta$-actin was included as a reference for protein normalization. Similar results were observed at least in three independent experiments. 


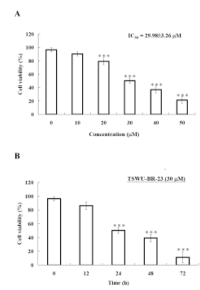

Figure 2.

Effects of compound $\mathbf{2 3}$ on cell viability of human colon adenocarcinoma cell line HT-29. Cells were treated with $0,10,20,30,40$ and $50 \mu \mathrm{M}$ of compound $\mathbf{2 3}$ for $24 \mathrm{~h}$ by MTT assay (A). Cells were treated with $30 \mu \mathrm{M}$ of compound $\mathbf{2 3}$ for 12, 24, 48 and $72 \mathrm{~h}$ by MTT assay (B) Results are presented as mean $\pm \mathrm{SD}$. The experiments were done in triplicate. $* * * \mathrm{p}<0.001$ 
A
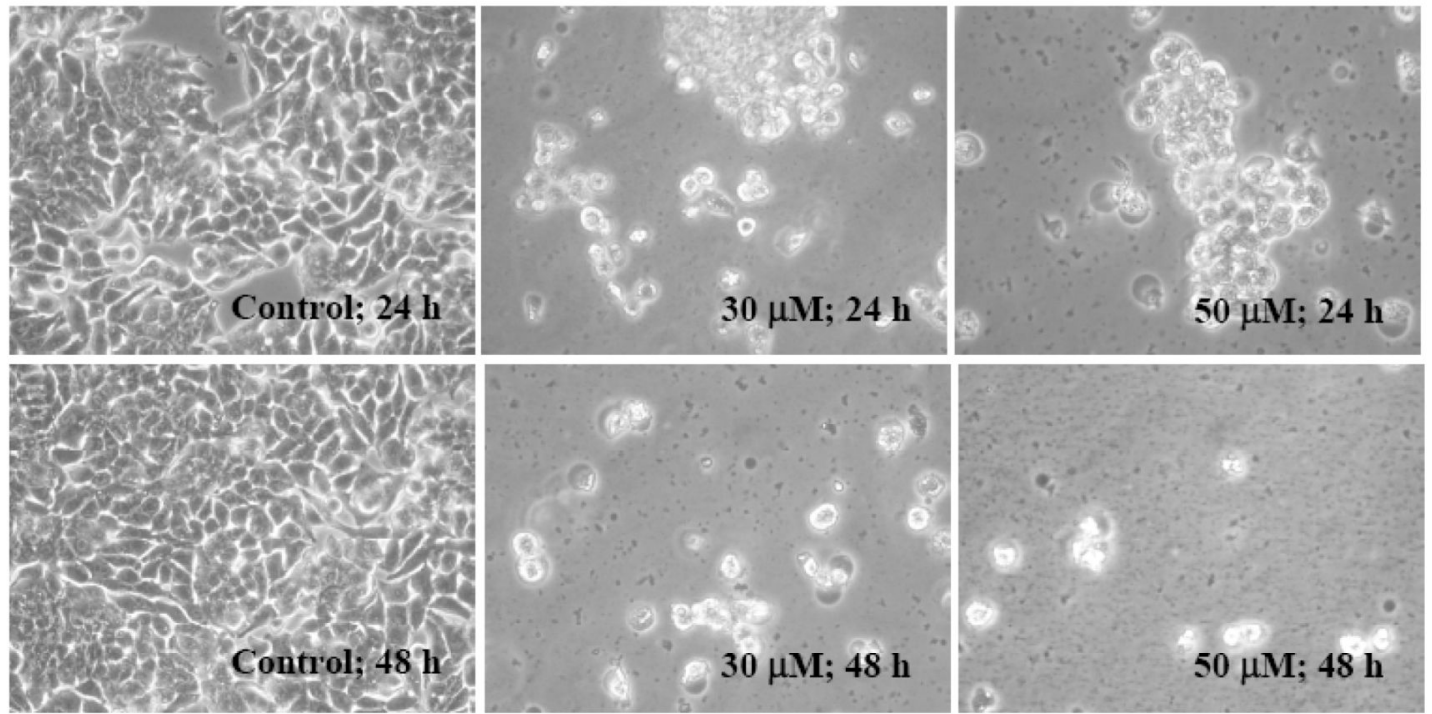

B
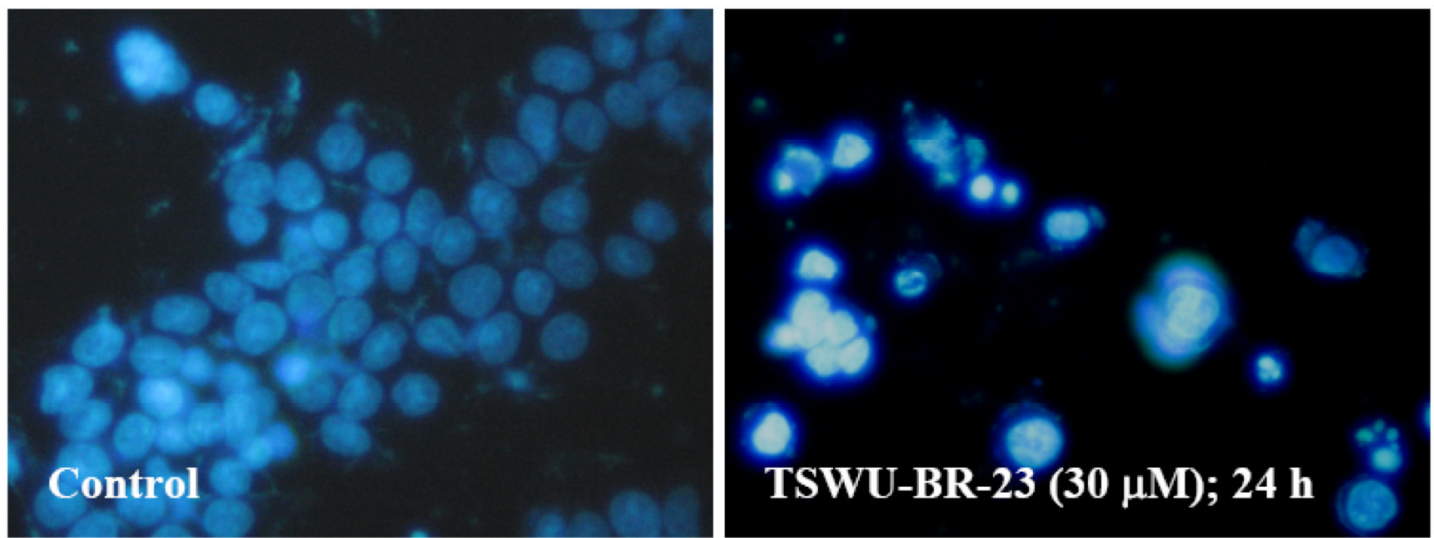

Figure 3.

Effects of compound $\mathbf{2 3}$ on cell morphological changes (A), and DNA condensation by DAPI staining (B) in human colon adenocarcinoma cell line HT-29. After incubation with compound 23 (30 and $50 \mu \mathrm{M}$ ) for 24 and $48 \mathrm{~h}$, cells exhibited nuclear shrinkage and chromatin condensation (A). DNA condensation was detected by DAPI staining (B). Cells were examined and photographed under fluoresce microscopy $(\times 200)$ as described in Materials and Methods. 


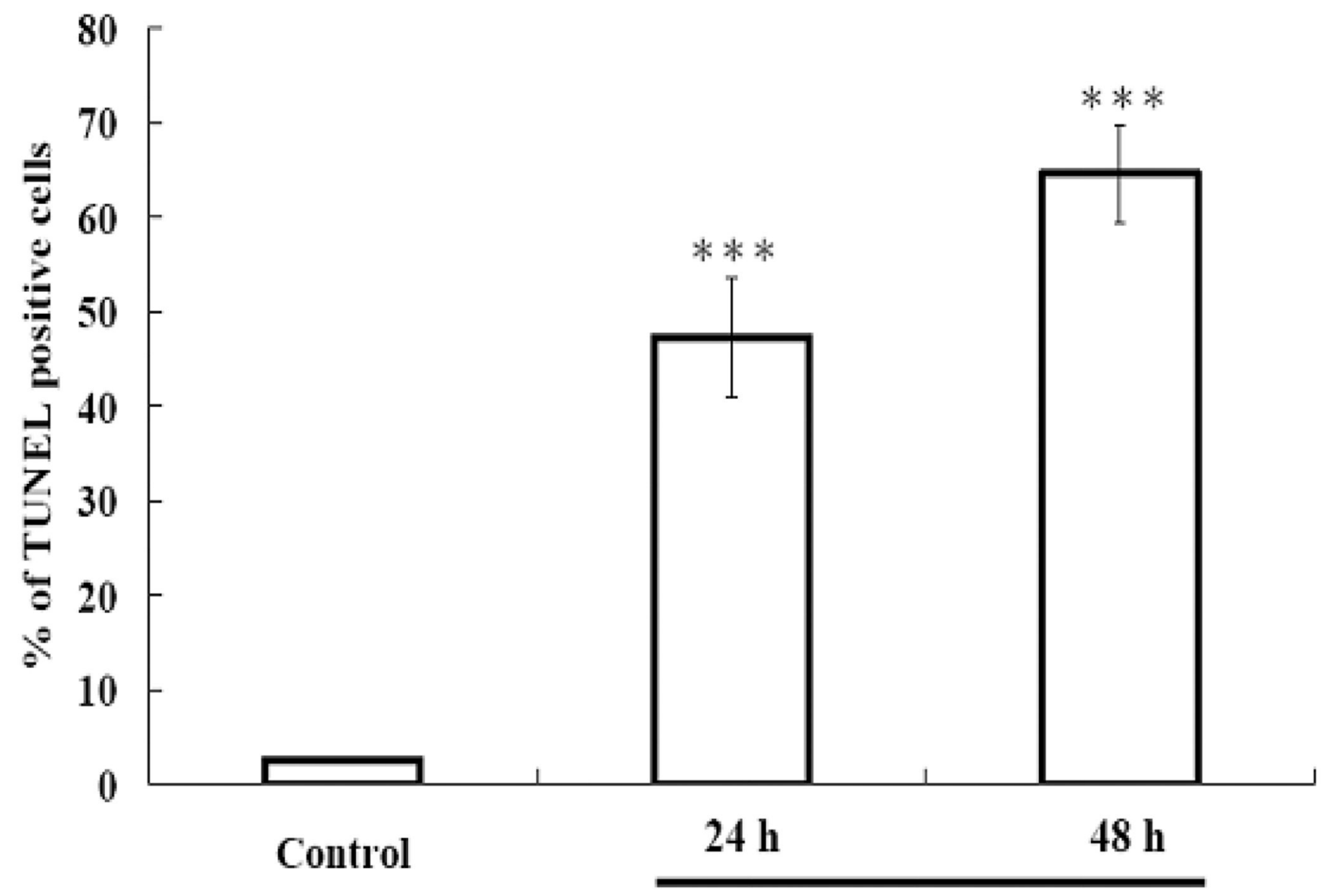

Figure 4.

Effects of compound $\mathbf{2 3}$ on DNA fragmentation in human colon adenocarcinoma cell line HT-29. HT-29 cells were treated with compound $23(30 \mu \mathrm{M})$ for 24 and $48 \mathrm{~h}$, then cells were stained with TUNEL and analyzed by FACScan flow cytometry. The experiments were done in triplicate. $* * * \mathrm{p}<0.001$ 


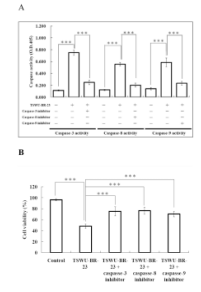

Figure 5.

Effects of compound $\mathbf{2 3}$ on caspase-3, caspase- 8 and caspase- 9 activity in human colon adenocarcinoma cell line HT-29 (A) and effects of caspase- 3 , caspase- 8 , and caspase- 9 inhibitors on cell viability in compound 23-treated HT-29 cells (B). Cells were pretreated with the caspase-3 inhibitor (Z-DEVE-FMK), caspase-8 inhibitor (Z-IETD-FMK) and caspase-9 inhibitor (Z-LEHD-FMK) for 1 hour and then treated with $30 \mu \mathrm{M}$ of compound 23 for 24 h. The total cell extracts were incubated with caspase-3, caspase-8, and caspase-9 specific substrates, respectively (Ac-DEVD-pNA, Ac-LEHD-pNA, and Ac-IETD-pNA). The release of pNA was measured at $405 \mathrm{~nm}$ by a spectrophotometer. For cell viability assay, cells were pretreated with the caspase- 3 , caspase- 8 and caspase- 9 inhibitor for $1 \mathrm{~h}$ and then treated with $30 \mu \mathrm{M}$ of compound 23 for $24 \mathrm{~h}$ by MTT assay. The experiments were done in triplicate. $* \mathrm{p}<0.05, * * \mathrm{p}<0.01, * * * \mathrm{p}<0.001$ 
A

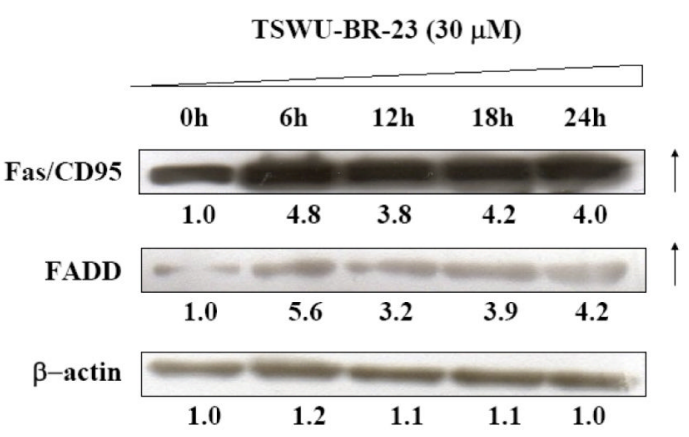

C

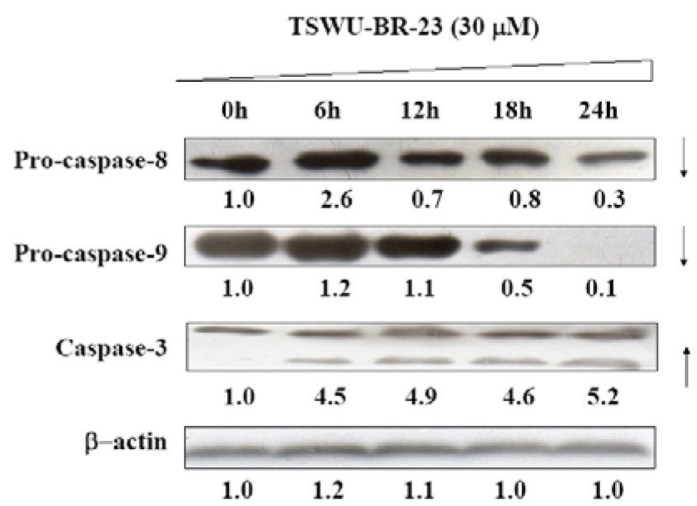

B

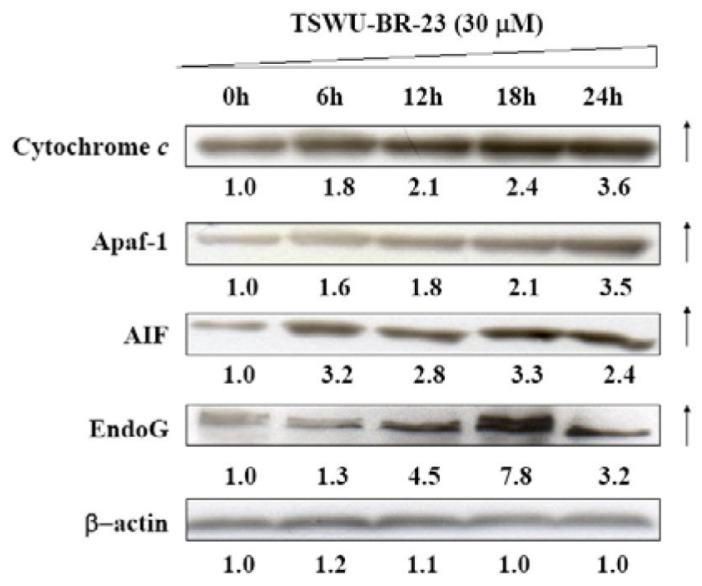

D

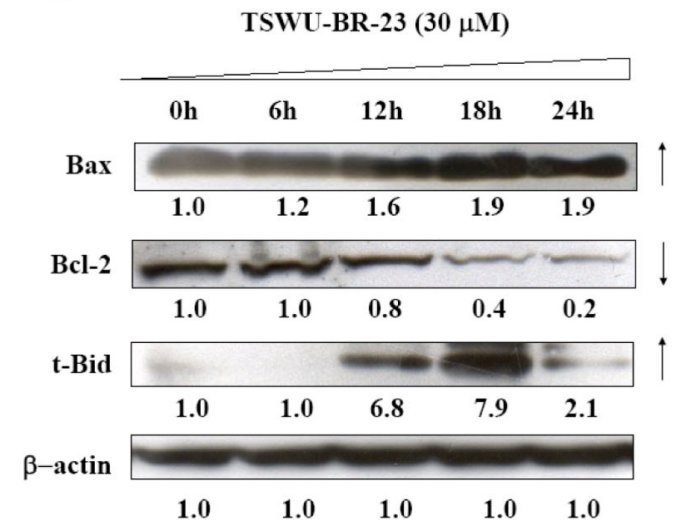

Figure 6.

Effects of compound 23-induced apoptotic relative protein levels on HT-29 cells. Western blotting analysis for (A) Fas/CD95 and FADD; (B) cytosolic cytochrome $c$, Apaf-1, AIF and Endo G; (C) pro-caspase-8, pro-caspase-9 and caspase-3; (D) Bax, Bcl-2 and t-Bid protein levels in compound $\mathbf{2 3}$ treated HT-29 cells. For Western blotting analysis, total or cytosolic protein extracts were analyzed by immunoblotting. 


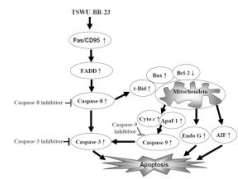

Figure 7.

A proposed model for the apoptosis signaling pathways in 23-treated HT-29 cells. 


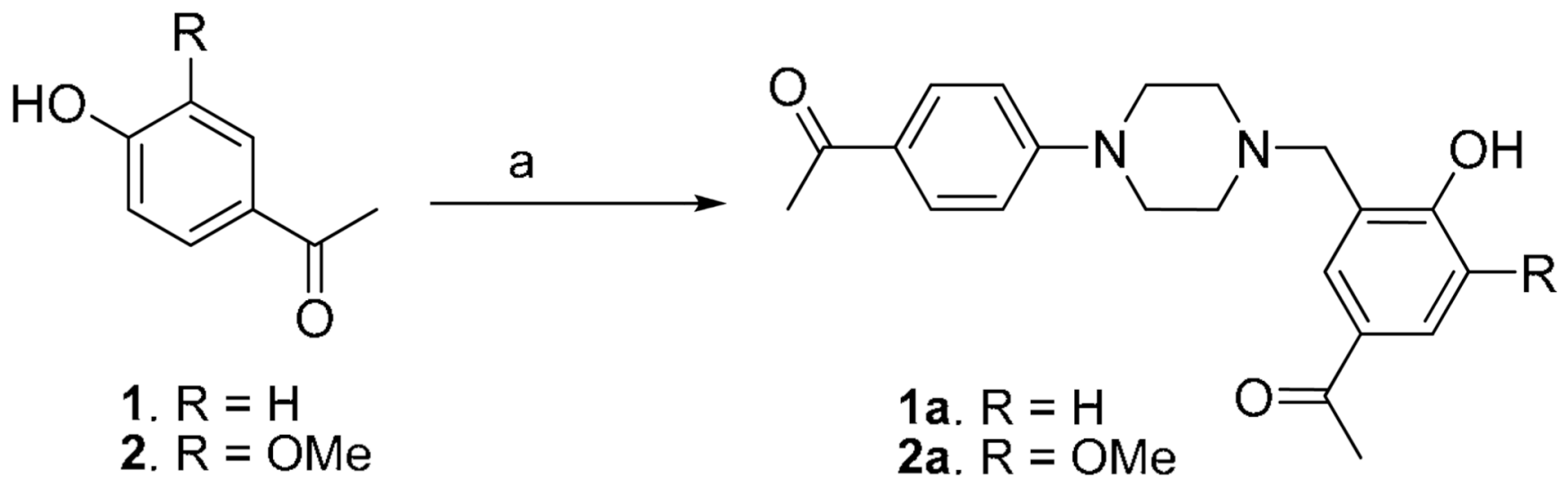

Scheme 1.

(a) Reagents and conditions: 4-piperizino acetophenone, paraformaldehyde, EtOH reflux at $120^{\circ} \mathrm{C}$ in $18-22 \mathrm{~h}$ 
1a (for 3-14)

2a (for 15-20)

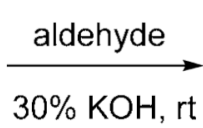

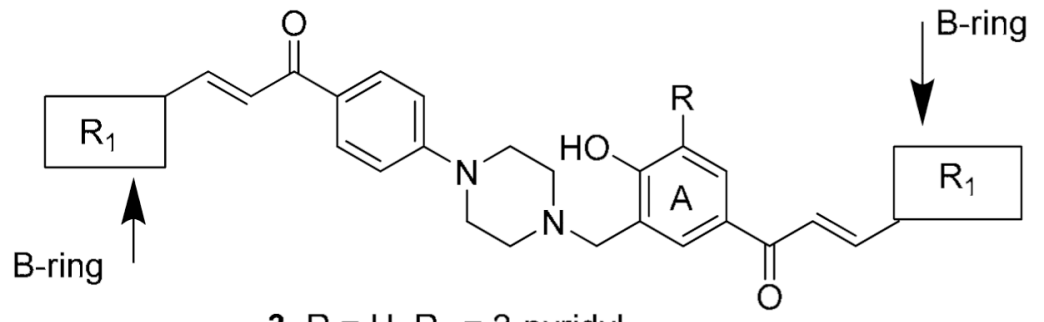

3. $\mathrm{R}=\mathrm{H}, \mathrm{R}_{1}=2$-pyridyl

4. $\mathrm{R}=\mathrm{H}, \mathrm{R}_{1}=3$-pyridyl

5. $\mathrm{R}=\mathrm{H}, \mathrm{R}_{1}=2$-furan

6. $\mathrm{R}=\mathrm{H}, \mathrm{R}_{1}=2$-thiophene

7. $\mathrm{R}=\mathrm{H}, \mathrm{R}_{1}=3$-methyl-2-thiophene

8. $R=H, R_{1}=5$-methyl-2-furan

9. $\mathrm{R}=\mathrm{H}, \mathrm{R}_{1}=\mathrm{N}$-methyl pyrrole

10. $R=H, R_{1}=$ phenyl

11. $\mathrm{R}=\mathrm{H}, \mathrm{R}_{1}=4$-methoxybenzene

12. $R=H, R_{1}=3,4$-methylenedioxybenzene

13. $\mathrm{R}=\mathrm{H}, \mathrm{R}_{1}=2$-chlorobenzene

14. $R=H, R_{1}=2$,4-dichlorobenzene

15. $\mathrm{R}=\mathrm{OMe}, \mathrm{R}_{1}=2$-thiophene

16. $R=O M e, R_{1}=3$-methyl-2-thiophene

17. $R=O M e, R_{1}=$ phenyl

18. $R=O M e, R_{1}=4$-methoxybenzene

19. $\mathrm{R}=\mathrm{OMe}, \mathrm{R} 1=2$-chlorobenzene

20. $R=$ OMe, $R 1=2$-pyridyl

Scheme 2. 

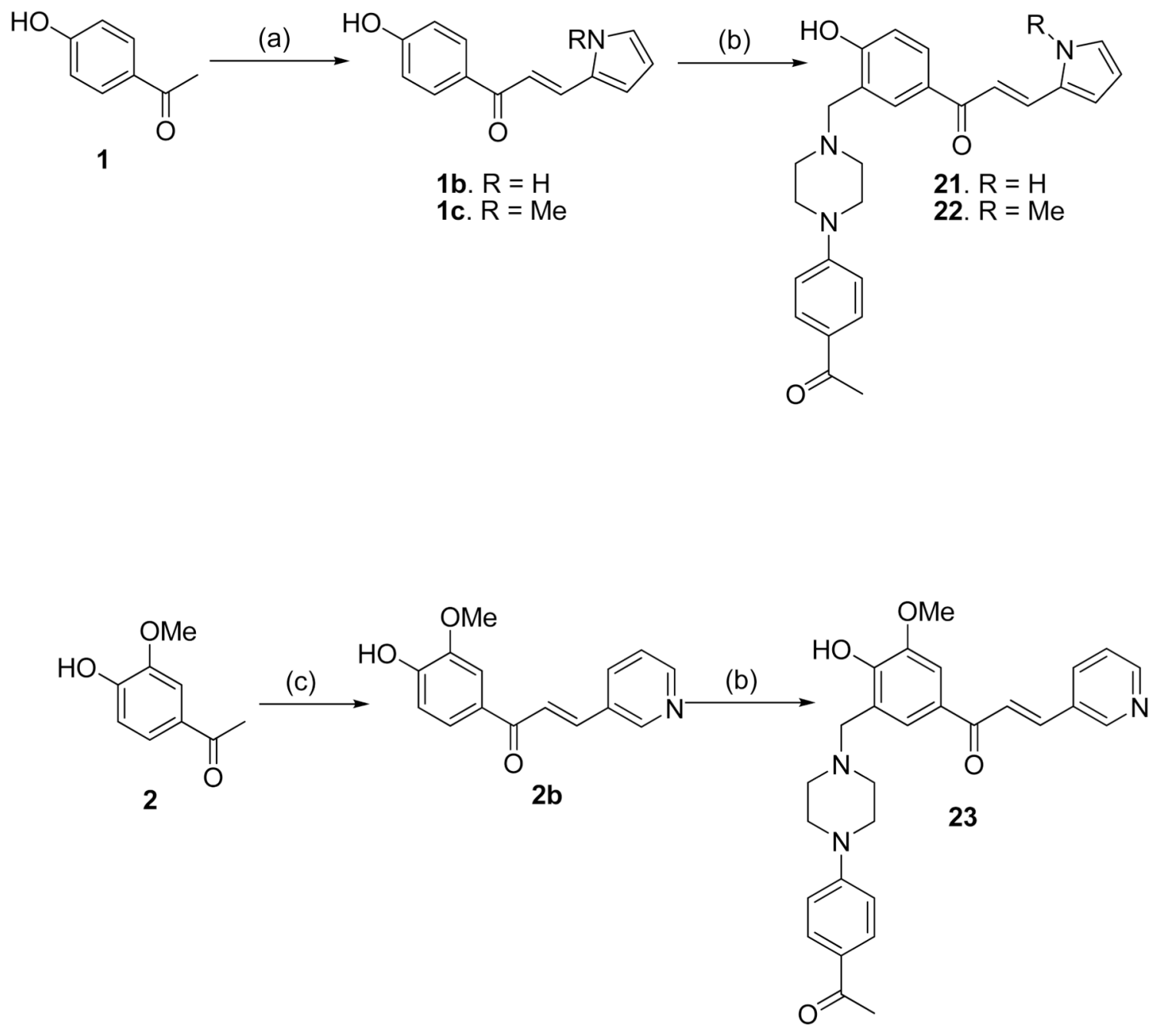

Scheme 3.

Reagents and conditions:

(a) for $\mathbf{1 b}$ from 1, pyrrole-2-carboxaldehyde, $\mathrm{MeOH}, 30 \% \mathrm{KOH}, \mathrm{rt}, 24 \mathrm{~h}$. for $1 \mathrm{c}$ from 1, Nmethylpyrrole-2-carboxaldehyde, $\mathrm{MeOH}, 30 \% \mathrm{KOH}, \mathrm{rt}, 24 \mathrm{~h}$.

(b) 4-piperizino acetophenone, paraformaldehyde, EtOH reflux at $120^{\circ} \mathrm{C}$ in $18-22 \mathrm{~h}$.

(c) for $\mathbf{2 b}$ from 2, 3-pyridinecarboxaldehyde, $\mathrm{MeOH}, 30 \% \mathrm{KOH}, \mathrm{rt}, 24 \mathrm{~h}$. 
Table 1

Summary of the effects of 1-23 on NOS activity in murine microglial cells ${ }^{a, b}$

\begin{tabular}{|c|c|c|r|}
\hline compound & $\mathbf{I C}_{\mathbf{5 0}}(\boldsymbol{\mu M})$ & compound & $\mathbf{I C}_{\mathbf{5 0}}(\boldsymbol{\mu M})$ \\
\hline $\mathbf{1 a}$ & $6.6 \pm 1.3^{*}$ & $\mathbf{1 3}$ & $30.5 \pm 11.4$ \\
\hline $\mathbf{2 a}$ & $15.9 \pm 1.5$ & $\mathbf{1 4}$ & $25.7 \pm 4.6$ \\
\hline $\mathbf{3}$ & $1.4 \pm 0.2$ & $\mathbf{1 5}$ & $2.7 \pm 0.3$ \\
\hline $\mathbf{4}$ & $0.3 \pm 0.0$ & $\mathbf{1 6}$ & $3.1 \pm 0.1$ \\
\hline $\mathbf{5}$ & $1.7 \pm 0.2$ & $\mathbf{1 7}$ & $2.1 \pm 0.4$ \\
\hline $\mathbf{6}$ & $1.9 \pm 0.0$ & $\mathbf{1 8}$ & $3.5 \pm 0.8$ \\
\hline $\mathbf{7}$ & $7.5 \pm 1.6$ & $\mathbf{1 9}$ & $10.9 \pm 2.8$ \\
\hline $\mathbf{8}$ & $2.4 \pm 0.2$ & $\mathbf{2 0}$ & $1.6 \pm 0.3$ \\
\hline $\mathbf{9}$ & $1.2 \pm 0.4$ & $\mathbf{2 1}$ & $1.7 \pm 0.3$ \\
\hline $\mathbf{1 0}$ & $2.8 \pm 0.5$ & $\mathbf{2 2}$ & $1.9 \pm 0.3$ \\
\hline $\mathbf{1 1}$ & $0.5 \pm 0.0$ & $\mathbf{2 3}$ & $3.5 \pm 0.4$ \\
\hline $\mathbf{1 2}$ & $2.1 \pm 0.2$ & $\mathrm{~L}-\mathrm{NAME}$ & $18.9 \pm 3.2$ \\
\hline
\end{tabular}

${ }^{a}$ NOS activity was measured by NO production in the presence of $1-50 \mu \mathrm{M}$ of drug. DPI (diphenyleneiodonium, a NOX inhibitor) was included as a positive control. Data were calculated as $50 \%$ inhibitory concentration (IC50) and expressed as means \pm SEM from 3 to 6 experiments performed on different days using microglial cells from different passages.

$*$ *

P $P 0.05$ as compared with relative positive controls, respectively.

${ }^{b}$ Compounds were also tested in NOX and DPPH assays, but none of the compounds were active. NOX activity was measured by ROS production, and DPI (a NOX inhibitor) was included as positive control (IC $500.4 \pm 0.2 \mu \mathrm{M}$ ). For the DPPH assay, Trolox (an antioxidant) was the positive control (IC50 $36.0 \pm 3.5 \mu \mathrm{M})$ 
Table 2

Cytotoxic activity data for $\mathbf{1} \mathbf{a}-\mathbf{2 3}^{a}$

\begin{tabular}{crrrr}
\hline \multirow{2}{*}{ Cmpd } & \multicolumn{4}{c}{ GI $_{\mathbf{5 0}}(\boldsymbol{\mu M})$} \\
\cline { 2 - 5 } & $\mathbf{K B}$ & $\mathbf{A 5 4 9}$ & HCT-8 & DU145 \\
\hline $\mathbf{3}$ & 1.23 & 1.08 & 1.26 & 1.25 \\
\hline $\mathbf{4}$ & 1.66 & 1.47 & 1.40 & 2.19 \\
\hline $\mathbf{1 7}$ & $>37.00$ & $>37.00$ & $>37.00$ & 29.20 \\
\hline $\mathbf{2 0}$ & 35.80 & $>35.80$ & 25.80 & $>35.80$ \\
\hline $\mathbf{2 1}$ & 19.00 & 20.10 & 24.70 & 17.90 \\
\hline $\mathbf{2 2}$ & 39.10 & 31.20 & $>45.10$ & $>45.10$ \\
\hline $\mathbf{2 3}$ & 13.10 & 9.77 & 11.25 & 9.98 \\
\hline Paclitaxel & $5.16 \mathrm{nM}$ & $7.6 \mathrm{nM}$ & $>100 \mathrm{nM}$ & $5.23 \mathrm{nM}$ \\
\hline
\end{tabular}

${ }^{a}$ Compounds that are not shown did not reach $50 \%$ inhibition at $20 \mu \mathrm{g} / \mathrm{mL}$ and are considered inactive. 